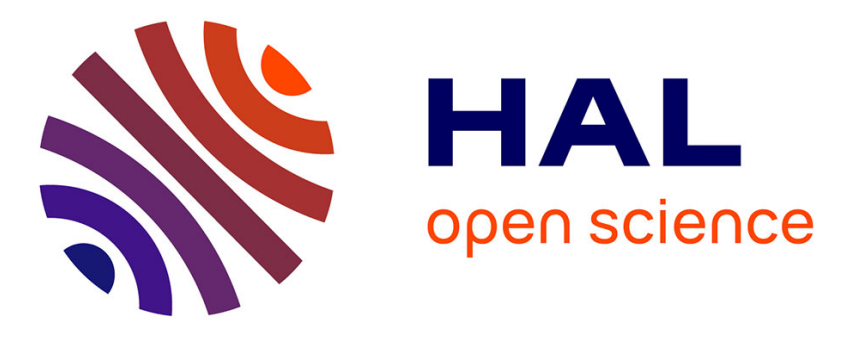

\title{
Experimental determination of the curvature-induced intra-wall polarization of inorganic nanotubes
}

Marie-Claire Pignié, Sabyasachi Patra, Lucie Huart, Aleksandar R

Milosavljević, Jean Philippe Renault, Jocelyne Leroy, Christophe Nicolas, Olivier Sublemontier, Sophie Le Caër, Antoine Thill

\section{To cite this version:}

Marie-Claire Pignié, Sabyasachi Patra, Lucie Huart, Aleksandar R Milosavljević, Jean Philippe Renault, et al.. Experimental determination of the curvature-induced intra-wall polarization of inorganic nanotubes. Nanoscale, 2021, 13, pp.19650-19662. 10.1039/D1NR06462B . cea-03442138

\section{HAL Id: cea-03442138 https://hal-cea.archives-ouvertes.fr/cea-03442138}

Submitted on 23 Nov 2021

HAL is a multi-disciplinary open access archive for the deposit and dissemination of scientific research documents, whether they are published or not. The documents may come from teaching and research institutions in France or abroad, or from public or private research centers.
L'archive ouverte pluridisciplinaire HAL, est destinée au dépôt et à la diffusion de documents scientifiques de niveau recherche, publiés ou non, émanant des établissements d'enseignement et de recherche français ou étrangers, des laboratoires publics ou privés. 


\title{
Experimental determination of the curvature-induced intra-wall polarization of inorganic nanotubes
}

Marie-Claire Pignié, ${ }^{a}$ Sabyasachi Patra, ${ }^{a}$ Lucie Huart, ${ }^{a}$ Aleksandar R. Milosavljević, ${ }^{b}$ Jean Philippe Renault, ${ }^{a}$ Jocelyne Leroy, ${ }^{a}$ Christophe Nicolas, ${ }^{b}$ Olivier Sublemontier, ${ }^{a}$ Sophie Le Caër ${ }^{a *}$ and Antoine Thilla*

${ }^{\text {aNIMBE, UMR }} 3685$ CEA, CNRS, Université Paris-Saclay, CEA Saclay 91191 Gif-surYvette Cedex, France

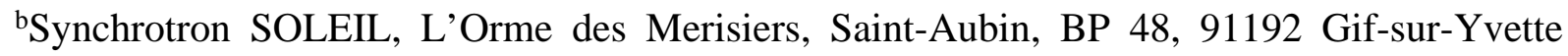
Cedex, France.

*corresponding authors: $\underline{\text { sophie.le-caer@cea.fr and antoine.thill@cea.fr }}$

\begin{abstract}
Inspired from a natural nano-mineral known as imogolite, aluminosilicate inorganic nanotubes are appealing systems for photocatalysis. One is completely hydrophilic (IMO$\mathrm{OH}$ ), while the other has a hydrophilic exterior and a hydrophobic interior $\left(\mathrm{IMO}-\mathrm{CH}_{3}\right)$, enabling the encapsulation of organic molecules. We combined UV-Vis diffuse reflectance spectroscopy of imogolite powders and synchrotron X-ray photoelectron spectroscopy of deposited imogolite films and isolated nanotubes to obtain not only the band structure, but also the quantitative intra-wall polarization of both synthetic imogolites for the first time. The potential difference across the imogolite wall was determined to be $0.7 \mathrm{~V}$ for IMO-OH and around $0.2 \mathrm{~V}$ for IMO- $\mathrm{CH}_{3}$. The high curvature of the nanotubes, together with the thinness of their wall, favors efficient spontaneous charge separation and electron exchange reactions on both the internal and external nanotube surfaces. In addition, the positions of their valence and conduction band edges make them interesting candidates for co-catalysts or doped catalysts for water splitting, among other possible photocatalytic reactions relevant to energy and the environment.
\end{abstract}

\section{Introduction}

Photocatalysts, especially semiconducting heterogeneous photocatalysts, ${ }^{1}$ are of great interest in energy and environmental applications. Efficient photocatalysts are able to facilitate the separation and migration of the electron-hole pairs that are generated upon irradiation, in order to reduce radiative and non-radiative recombination losses. ${ }^{1-2}$ This is critical to important processes such as the photoreduction of water or carbon dioxide for energy 
production or for the generation of reactive oxygen species that can oxidize carbon-based molecules in pollution remediation and biological applications. One strategy to achieve the required level of performance is photoelectrocatalysis, in which an external bias voltage is applied to the photocatalyst, which drives the electron-hole pairs into opposite directions, therefore reducing their recombination rate. Alternatively, the recombination of charge carriers can be limited by the presence of an electric field within the photo-active material itself. For example, one can apply a periodic pressure to piezoelectric materials or develop ferroelectric materials with spontaneous polarizations. ${ }^{3}$ However, in all these cases, the charge recombination is limited by the application of an external force, which enables driving the charge carriers in opposite directions. A second strategy consists of favoring the transport of charge carriers toward surfaces in order to maximize the probability that the desired chemical reactions take place. This can be very effectively realized by using hollow nanostructures with thin walls in order to reduce the electron/hole recombination probability. ${ }^{4}$ However, without polarization, there is no significant physical separation of the charge carriers. The combination of polarization and hollowness could be very rewarding, as it would enable spatial separation of the charge carriers toward nearby internal and external surfaces where both redox reactions are favored on distinct surfaces. ${ }^{4}$

Among various hollow nanostructures (carbon nanotubes, ${ }^{5}$ sepiolite, halloysite, allophane, microemulsions...), imogolite appears as a promising material for photocatalytic applications. Imogolite $\left((\mathrm{OH})_{3} \mathrm{Al}_{2} \mathrm{O}_{3} \mathrm{Si}(\mathrm{OH})_{2}\right.$ or IMO-OH) is a natural aluminosilicate nanotube $(\mathrm{NT})$, made of only non-toxic and abundant elements. It presents a well-defined tubular shape with a monodisperse internal diameter of $1.4 \mathrm{~nm}$. A mismatch between the Al-octahedra and the Sitetrahedra sheets and internal water-wall interactions induces a differential interfacial tension between both surfaces of imogolites. ${ }^{6}$ This differential tension combined with the flexibility of the dioctahedral aluminum sheet leads to a spontaneous curvature. The curvature of imogolite nanotubes has been well described by Molecular Dynamic simulations and elegantly reproduced by the simple equation proposed by Guimaraes et al. ${ }^{7}$ The mechanical energy per unit surface area as a function of the curvature radius $r$ can be expressed as: ${ }^{6}$

$$
E=\frac{Y h^{3}}{3 r^{2}}-\Delta \sigma \frac{h}{r}+\Sigma(E q .1)
$$

where the first term corresponds to the strain energy (with $Y$ the Young modulus of a 2D slab of thickness $2 h$ ); the second one to interfacial energy, with $\Delta \sigma$ the difference in surface 
tension between both surfaces and the last one to the sum of the internal and external surface tension. This last term is the value towards which the mechanical energy per unit surface area tends at large curvature radii. The second term is the driving force for curvature, estimated to be on the order of $4 \mathrm{~J} \cdot \mathrm{m}^{-2}{ }^{8}$ The curved surfaces are covered by hydroxyl groups paving both the inside $(\mathrm{Si}-\mathrm{OH})$ and the outside $\left(\mathrm{Al}_{2}-\mu \mathrm{OH}\right)$ of the NT surfaces. Since its first synthesis in $1977,{ }^{9-10}$ imogolite has proven to be easily synthesized with cheap reactants. Moreover, its chemical functions can be tuned while preserving the nanotubular structure. ${ }^{11}$ In particular, hybrid imogolites can be prepared with internal surfaces covered by $\mathrm{Si}-\mathrm{CH}_{3}$ groups $\left(\mathrm{IMO}-\mathrm{CH}_{3}\right)^{12}$ or by a mixture of chemical groups, ${ }^{13}$ while external surfaces remain hydrophilic for easy dispersal in water. Moreover, $\mathrm{IMO}-\mathrm{CH}_{3}$ is able to encapsulate small organic molecules. ${ }^{13-14}$, and thus may act as a 1D inorganic hydrophobic nanoreservoir.

Early analysis of the surface chemistry of imogolite revealed that the evolution of the surface charge with $\mathrm{pH}$ cannot be explained exclusively by the $\mathrm{pKa}$ of the various surface hydroxyl groups using the Stern model. ${ }^{15}$ For IMO-OH, a constant external charge (independent of $\mathrm{pH}$ ) on the order of $42 \mathrm{mC} \cdot \mathrm{m}^{-2}$ was required to properly fit the observed surface charge. ${ }^{15}$ Recent DFT calculations have shown that the extreme curvature of these NTs induces a deformation of the distribution of the electronic density, giving rise to an accumulation of negative (positive) charge on the inner (outer) surface of the NTs. ${ }^{16-18}$ The excess positive charge was estimated to be $21 \mathrm{mC} \cdot \mathrm{m}^{-2}$ and $13 \mathrm{mC} \cdot \mathrm{m}^{-2}$ for models of IMO-OH and IMO- $\mathrm{CH}_{3}$ NTs, respectively, if one assumes a physical wall thickness of $5.5 \AA .{ }^{18}$ The existence of charge accumulation and an internal electric field was evidenced experimentally by our group using the encapsulation of a solvatochromic dye, the Nile Red, within the IMO- $\mathrm{CH}_{3}$ cavity ${ }^{13}$ and, more recently, by using pulse radiolysis. ${ }^{19}$ The presence of this intra-wall electric field implies charge separation effects, with generated electrons driven outward and holes driven inward. The hollowness of the nanotubes and their extremely thin wall (5.5 ̊) favor efficient energy transfer, and additionally, reactivity at the nanotube interfaces. Until now, experimental studies of the wall polarization of imogolite have only been qualitative, and the band diagram of imogolite has never been determined experimentally. Yet, this knowledge is crucial to assess the potential of imogolite as a photocatalyst, where the band structure diagram provides insights on which chemical reactions would be thermodynamically allowed.

The purpose of this article is to combine experimental techniques to quantify the intrawall electric field, the band gap energy values and the energy positions of the valence and conduction bands for IMO-OH and $\mathrm{IMO}_{-} \mathrm{CH}_{3}$. To achieve this goal, we used UV-Vis diffuse 
reflectance spectroscopy to determine the band gap energy value along with $\mathrm{X}$-ray Photoelectron Spectroscopy (XPS) on dry films (laboratory experiments) and isolated nanoparticles (synchrotron radiation based XPS experiments). ${ }^{20}$ XPS provides information on the local environment of atoms, and more importantly, on the static electric field present in the material, which directly affects the kinetic energy of photoelectrons. It also enables positioning the valence band, ${ }^{21}$ and hence, once the band gap determined, the conduction band. All this knowledge will highlight the interest of these polarized nanotubes as cocatalysts or doped catalysts for various photocatalytic reactions relevant to important societal domains (energy and environment).

\section{Results and Discussion}

\subsection{Characterization of the synthesized imogolites}

\subsubsection{Characterization by Small-angle X-ray scattering (SAXS)}

The radial averaged SAXS profiles of imogolite (both IMO-OH and IMO- $\mathrm{CH}_{3}$ ) suspensions in water showing the dependence of the scattering intensity on the scattering vector are given in Figure 1 together with the simulated curves. The simulated parameters are displayed in Table 1. It is evident from Table 1 that there is a difference in the internal electronic density of the two imogolites. Indeed, IMO-OH is full of water whereas the $\mathrm{IMO}-\mathrm{CH}_{3}$ nanotube is partially empty. In this latter case, however, the internal electronic density value is not equal to zero, indicating the presence of some small molecule impurities.

Table 1. Characterization of both imogolites as obtained from SAXS curve fitting.

\begin{tabular}{|c|c|c|}
\hline Simulated parameters & IMO-OH & $\mathrm{IMO}_{\mathrm{C}} \mathrm{CH}_{3}$ \\
\hline Internal radius $(\AA)$ & 9 & 10 \\
\hline Wall thickness $(\AA)$ & \multicolumn{2}{|c|}{5.5} \\
\hline Number of Si atoms per ring & 14 & 16 \\
\hline Lattice parameter $(\AA)$ & \multicolumn{2}{|c|}{4.3} \\
\hline $\begin{array}{c}\text { Internal electronic density } \\
\left(\mathrm{e}^{-} . \AA^{-3}\right)\end{array}$ & 0.33 & 0.18 \\
\hline $\begin{array}{l}\text { External electronic density } \\
\left(\mathrm{e}^{-} . \AA^{\circ}\right)\end{array}$ & \multicolumn{2}{|c|}{0.33} \\
\hline
\end{tabular}




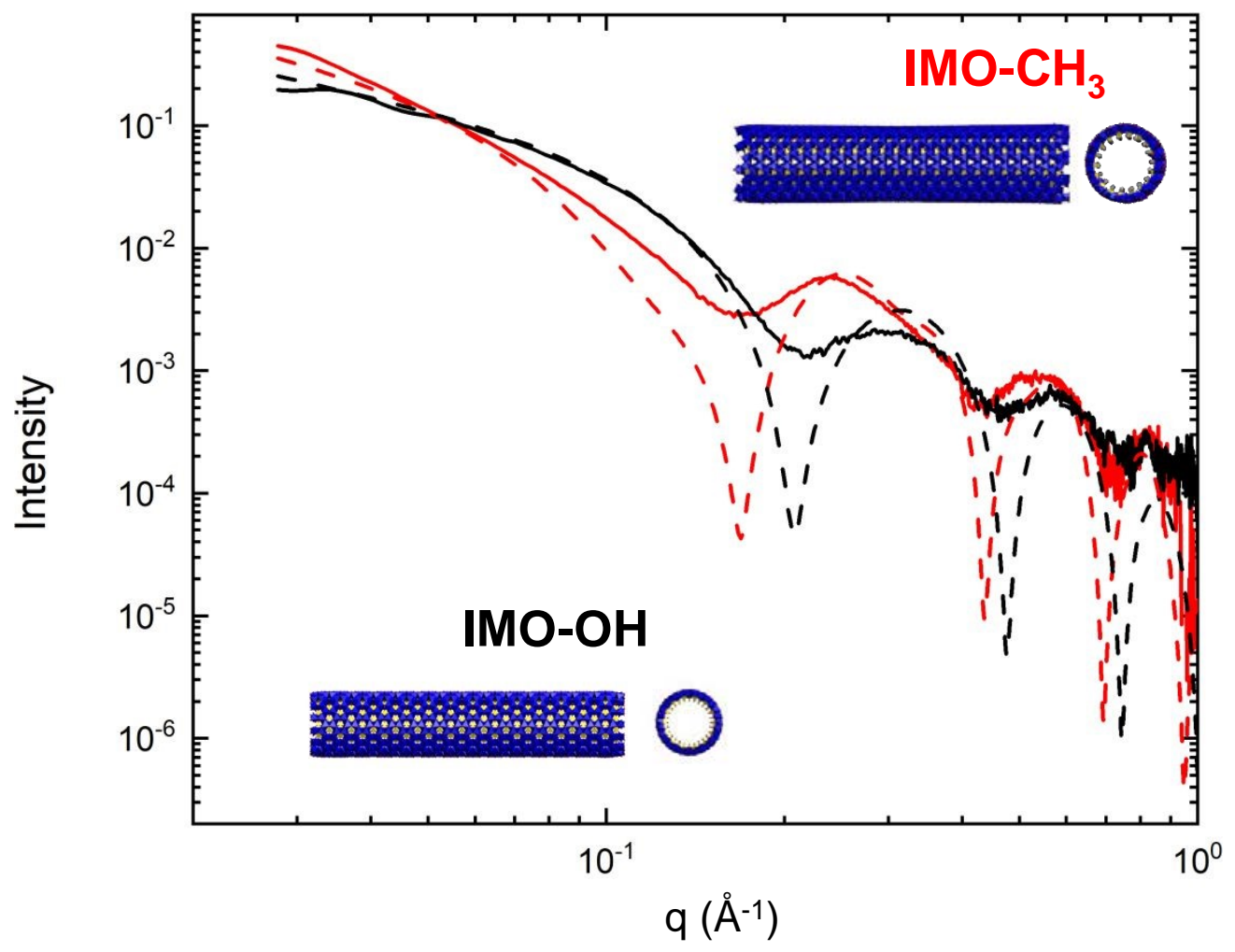

Figure 1. Small-angle $x$-ray scattering curves of imogolite (IMO-OH, black curve) and hybrid imogolite (IMO-CH , red curve). Dashed curves show the respective simulated SAXS profiles. The corresponding parameters are given in Table 1. 3D models of the front and side views of $\mathrm{IMO}-\mathrm{OH}$ and $\mathrm{IMO}_{-} \mathrm{CH}_{3}$ are displayed at the bottom and at the top of the figure, respectively.

Imogolite samples were also characterized by Cryo-TEM and infrared spectroscopy experiments. The Cryo-TEM and FT-IR spectra are given in Figures SI-1 and SI-2 in Supporting Information, respectively.

Eosin $\mathrm{Y}$ was encapsulated within the cavity of $\mathrm{IMO}-\mathrm{CH}_{3}$. This compound was chosen as it is an electron-rich dye whose presence in the nanotube can be followed easily by SAXS since it possesses four bromine atoms (Figure 2a). Figure 2a gives the radially averaged SAXS profiles of Imo- $\mathrm{CH}_{3}$ without and with eosin Y. The position of the first intensity minimum is linked to the internal electronic density of the nanotubes. ${ }^{14}$ The shift of this first minimum can thus be used to estimate the concentration of eosin $\mathrm{Y}$ within the $\mathrm{Imo}_{-} \mathrm{CH}_{3}$ cavity.

The volume of an IMO- $\mathrm{CH}_{3}$ unit lattice ring was calculated as $1351 \AA^{3}$ using the lattice parameter $(4.3 \AA)$ and the internal radius $(10 \AA)$. The difference in internal electron density between pristine IMO- $\mathrm{CH}_{3}$ and eosin $\mathrm{Y}$ encapsulated $\mathrm{IMO}-\mathrm{CH}_{3}$ was 0.10 , with an increased 
density of $0.28 \mathrm{e}^{-} \cdot \AA^{-3}$ for the latter. The number of eosin $\mathrm{Y}$ molecules in a lattice ring was calculated using the number of electrons per eosin Y molecule (308 electrons) and the lattice unit volume. In the case of the addition of eosin Y molecules to impurities that might already be present in the IMO- $\mathrm{CH}_{3}$ nanotube, the calculation yields 0.57 eosin $\mathrm{Y}$ molecules per lattice ring, or one eosin Y molecule every 1.75 lattice rings.

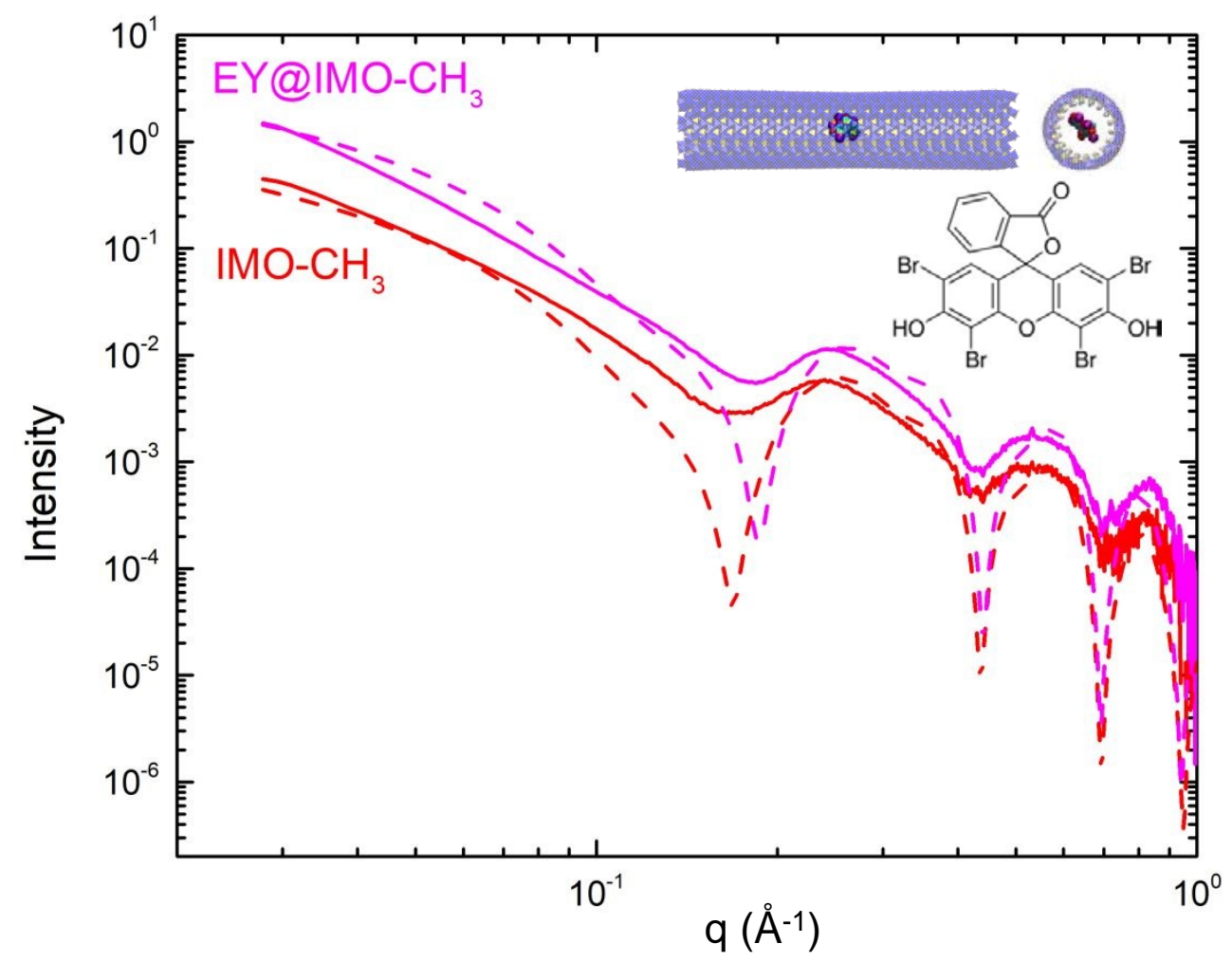

Figure 2. Hybrid imogolite (IMO-CH , red curve) and hybrid imogolite encapsulating eosin $\mathrm{Y}$ (EY@IMO-CH , pink curve). The shift in the first intensity minimum between $\mathrm{IMO}-\mathrm{CH}_{3}$ and EY@IMO-CH $\mathrm{CH}_{3}$ shows the increase of the electronic density inside the cavity. This proves the encapsulation of eosin $Y$ inside the hybrid imogolite. Dashed curves show the respective simulated SAXS profiles. The chemical structure of eosin $Y$, as well as front and side views of IMO-CH $\mathrm{CH}_{3}$ containing only one eosin $Y$ molecule, are given. The scheme is provided for illustrative purposes of encapsulation only.

2.1.2. Measurement of the band gap energy value by $U V$-Vis diffuse reflectance spectroscopy

UV-visible diffuse reflectance spectroscopy (DRS) is a commonly used method to determine the band gap energy $\left(\mathrm{E}_{\mathrm{g}}\right)$ of a semiconductor. ${ }^{22}$ The reflectance $(\%)$ measured in the 
wavelength range of 200-700 $\mathrm{nm}$ was transformed into the extinction coefficient $(\alpha)$ through the Kubelka-Munk $(F(R))$ function. $F(R)$ is expressed as:

$$
F(R)=\frac{(1-R)^{2}}{2 R}=\frac{k}{S}=\alpha(\text { Eq. } 2)
$$

with $R$ the absolute diffuse reflectance of an infinitely thick sample at a given wavelength. Notably, our samples were thick enough to satisfy the Kubelka-Munk condition of infinite sample thickness. ${ }^{23} k$ and $s$ correspond to the absorption and scattering coefficient of the material, respectively.

For a dense and infinitely thick sample composed of small particles having a size comparable to the wavelength of the incident light, the Kubelka-Munk function can be approximated. In this case, the optical band gap of the material can be obtained from the Tauc representation ${ }^{24-}$ 26 , as given in Eq. 3.

$$
(F(R) h v)^{1 / \gamma}=B\left(h v-E_{g}\right)(\text { Eq. 3) }
$$

with $h$ the Planck constant, $v$ the frequency of the photons, $E_{g}$ the value of the energy of the band gap and $B$ a constant. $\gamma$ is equal to $1 / 2$ or 2 for a direct or indirect band gap transition, respectively. In the present case, $\gamma$ was found to be equal to $1 / 2$ for both imogolite types (IMO$\mathrm{OH}$ and $\mathrm{IMO}-\mathrm{CH}_{3}$ ), which corresponds to a direct band gap transition (Figure 3). The value of the band gap was equal to $(5.85 \pm 0.30) \mathrm{eV}$ for $\mathrm{IMO}-\mathrm{OH}$ and to $(5.4 \pm 0.2) \mathrm{eV}$ for $\mathrm{IMO}-\mathrm{CH}_{3}$. 


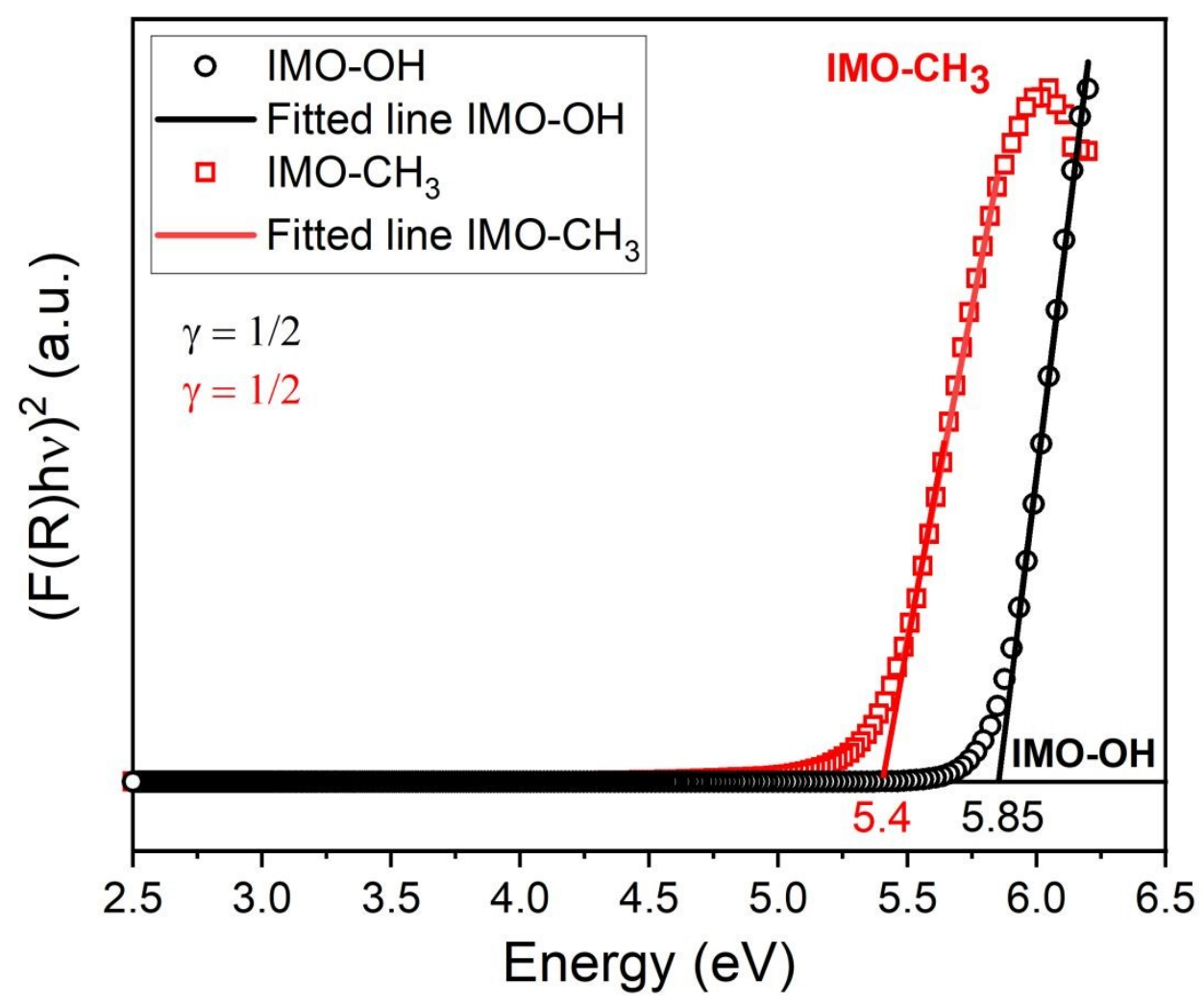

Figure 3. Band gap energy determination from the Tauc plot. The linear region is extrapolated to find the intercept on the energy axis for both imogolites (IMO-OH in black and $\mathrm{IMO}_{-} \mathrm{CH}_{3}$ in red). The value of $1 / 2$ for $\gamma$ indicates a direct allowed electronic transition for both types of imogolites. The value of the measured band gap energy is $5.85 \mathrm{eV}$ for IMO-OH and $5.4 \mathrm{eV}$ for $\mathrm{IMO}-\mathrm{CH}_{3}$.

\subsection{XPS analysis applied to IMO-OH and IMO-CH $\mathrm{CH}_{3} \mathrm{NT}$}

Two complementary XPS techniques were used to obtain information on the local environment of various atoms of interest and to build the band diagrams of both imogolites (see the experimental section). In the case of laboratory XPS, analysis was performed under high vacuum (1.3 x $10^{-9}$ mbar) on a surface-deposited sample. Under these conditions, external water was removed from both imogolites. However, most likely, internal water was still present inside IMO-OH NTs. ${ }^{27}$ The resulting spectra are expressed as a function of binding energy against the Fermi level (BE) after calibration using the $\mathrm{C} 1 \mathrm{~s}$ band of adventitious carbon positioned at $285.0 \mathrm{eV}$. Representative XPS spectra of both samples are shown in Figures $4 \mathrm{a}$ and $4 \mathrm{~b}$ for IMO-OH and $\mathrm{IMO}-\mathrm{CH}_{3}$, respectively. 
For synchrotron radiation-based soft X-ray photoelectron spectroscopy experiments, samples were isolated; there was no substrate interaction and no charging effects, as a free material jet was used and was continuously renewed under the photon beam. Moreover, the generation of the aerosol directly from the nanotube dispersion prevented the presence of any significant contamination, e.g. of adventitious carbon. In the aerosol, agglomerates of nanotubes are generated. These particles have a mean size of about $200 \mathrm{~nm}$ (see the experimental section and Figure SI-3 in the Supporting Information for the size distribution for both imogolites). Thus, contrary to the case of the deposited samples (Figure 4a), no carbon was detected in IMO-OH. In contrast, carbon was detected in $\mathrm{IMO}^{-\mathrm{CH}_{3}}$ (see Figure SI-4). Moreover, since under these conditions the nanoparticles are isolated (which means that they are not in contact with the spectrometer), the binding energy cannot be calibrated against the Fermi level, but is rather determined with respect to the vacuum level according to the known ionisation potentials (IPs) of either carrier gases $\left(\mathrm{Ar}\right.$ or $\left.\mathrm{N}_{2}\right)$ or solvent molecules $\left(\mathrm{H}_{2} \mathrm{O}\right)$ that are inevitably present in the interaction region. Note that the XPS lines of the gaseous targets are clearly distinguished from those of the focused nanoparticles (see reference ${ }^{28}$ for details). The given nanoparticle binding energy was calibrated according to the kinetic energy difference with respect to the closest IP of the carrier gas or the solvent gas, measured at the same photon energy. The linearity of the kinetic energy scale has been validated according to the position of $\mathrm{Ar} 2 \mathrm{~s}, 2 \mathrm{p}, 3 \mathrm{~s}$ and $3 \mathrm{p} \mathrm{IPs},{ }^{29}$, as well as Ar KLL Auger spectra ${ }^{30}$. As the binding energy of isolated nanoparticles is determined against the vacuum level, it corresponds to $\mathrm{BE}$ $+\mathrm{WF}$, WF being the work function of the material and BE being the binding energy determined against the Fermi level (see Figure 4c). It should be noted however that such conclusion is somewhat simplified because the near-surface vacuum level of the nanotubes agglomerates (generally used to define the WF - see reference ${ }^{31}$ ) might not be aligned with the vacuum level of the reference gas. However, this shift does not influence the comparison of the different samples, since the IP calibration is the same for all. The differences between the laboratory- and synchrotron radiation-based XPS experiments, corresponding to deposited and isolated samples, respectively, are depicted on Figure 4c. 


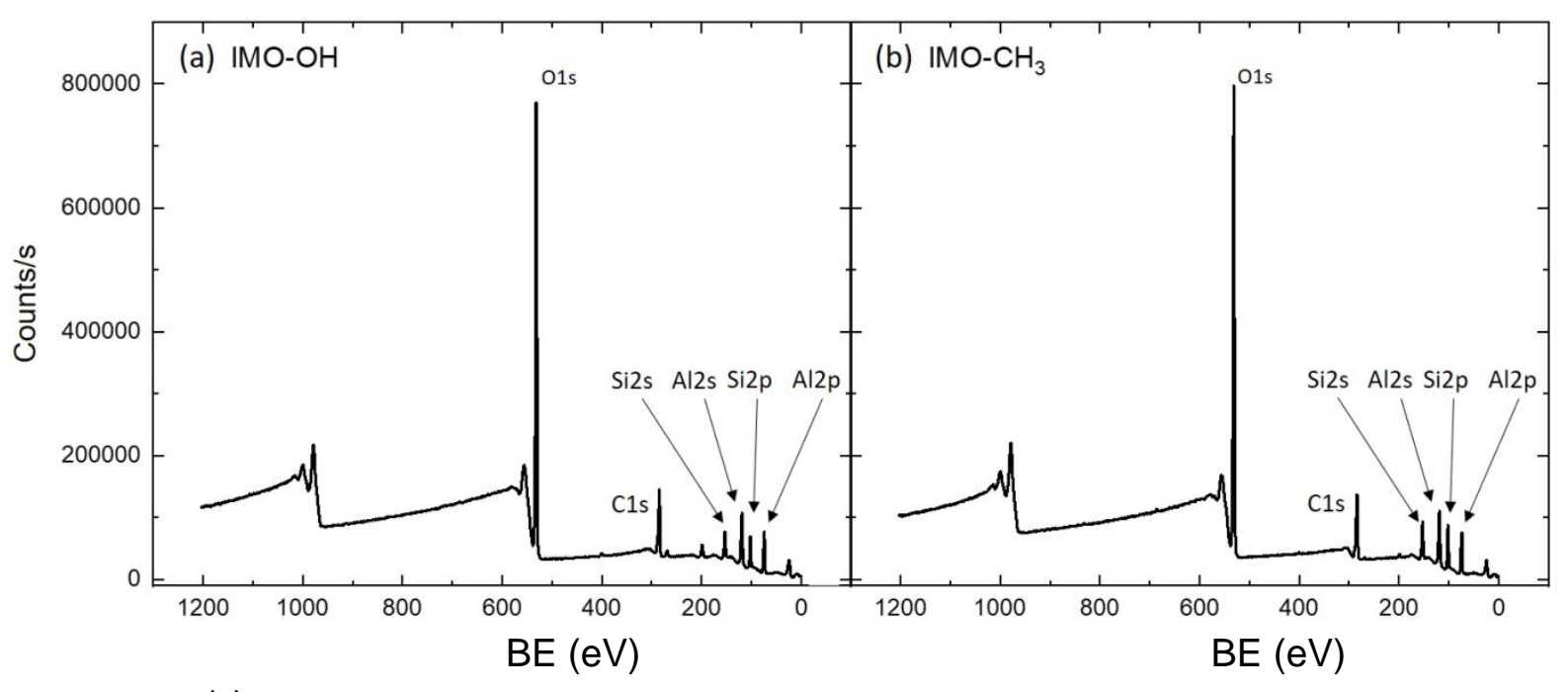

(c)

Deposited

Isolated

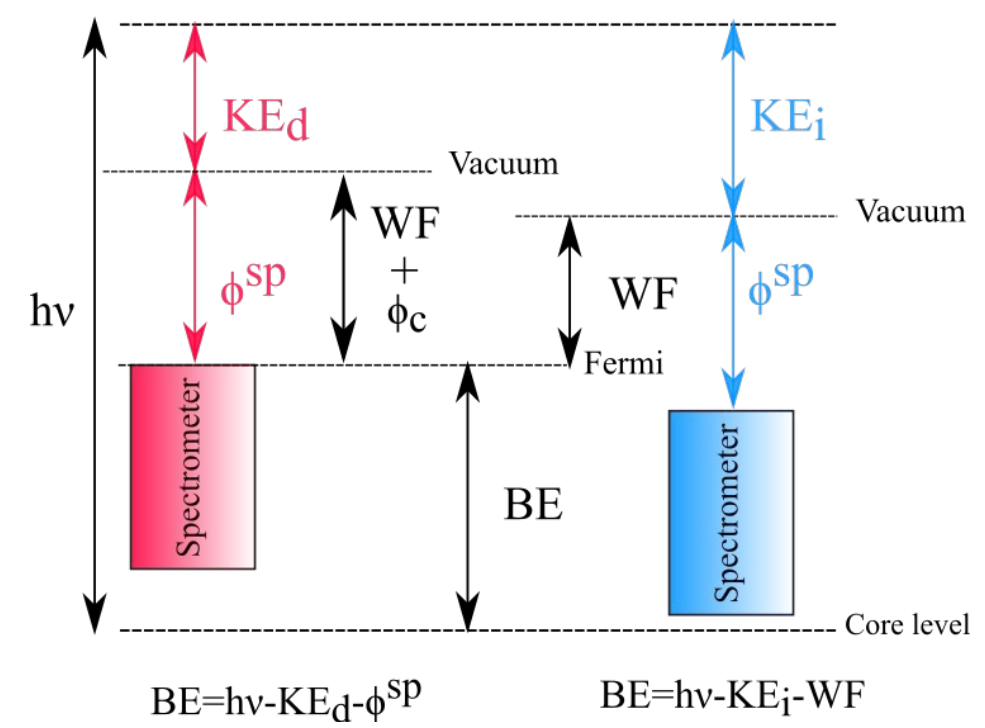

Figure 4. Representative XPS spectra of deposited IMO-OH (a) \& IMO-CH $(b)$ samples. Scheme of the physical principle of XPS and comparison of the techniques for deposited and isolated samples $(c)$. For the deposited samples, the atomic core level binding energy $(B E)$ is obtained with: $B E=h v-K E_{d}$ - $\Phi^{s p}$ where $h v$ is the energy of the incident photons. $K E_{d}$ is the photoelectron kinetic energy measured at the detector and $\Phi^{s p}$ is the work function of the spectrometer. It is an experimental constant, which is established during the calibration procedure. In the case where the spectrometer and the sample are in contact, the Fermi levels are aligned. Therefore, there is the appearance of a contact potential $\Phi_{c}$ which can be positive or negative. This implies that the work function cannot be directly measured on the deposited sample. In the case of isolated samples, the value of $K E_{i}$, measured with respect to vacuum, is obtained through the calibration with gases. The binding energy is obtained as $B E=h v-$ $K E_{i}-W F, K E_{i}$ being the kinetic energy measured at the detector and WF the sample work function. See reference ${ }^{32}$ for more details (see figure 19 from this reference with the corresponding discussion).

In synchrotron radiation-based XPS measurements, even if the aerosol goes through a drying chamber before being focused under vacuum, water is still likely to be present at the surface of the particles. ${ }^{21}$ Therefore, emitted photoelectrons always have to go through a layer of 
water before being detected. In order to test the depth sensitivity of the technique, spectra were collected from IMO- $\mathrm{CH}_{3}$ at two different incident photon energies (150 and $\left.400 \mathrm{eV}\right)$ in presence of encapsulated eosin Y (Figure 5), a dye containing four bromine atoms (Figure 2). In addition to the $\mathrm{Al} 2 \mathrm{p}$ contribution, another feature - barely detected at the $150 \mathrm{eV}$ energy appeared clearly at the higher photon energy (Figure 5). It is attributed to the $\mathrm{Br} 3 \mathrm{~d}$ core level spectrum and is characterized by a doublet separated by roughly $1 \mathrm{eV}: 3 \mathrm{~d}_{3 / 2}$ is located around $77.2 \mathrm{eV}$ whereas $3 \mathrm{~d}_{5 / 2}$ is located around $76.0 \mathrm{eV}$. As the thickness of the imogolite wall is equal to $5.5 \AA$, bromine photoelectrons were hardly detected with photons of $150 \mathrm{eV}$ incident energy, especially in presence of external water. In contrast, with $400 \mathrm{eV}$ photons, the $\mathrm{Br} 3 \mathrm{~d}$ line is clearly observed (Figure 5). For photons of 150 and $400 \mathrm{eV}$ energy, the $\mathrm{Br} 3 \mathrm{~d}$ photoelectrons have an attenuation length of roughly 4 and $10 \AA$ in aluminum ${ }^{33-34}$ (or in silicon), and of 1.0 and $1.5 \mathrm{~nm}$ in ice, ${ }^{35}$ respectively. Therefore, the comparison between the spectra measured at both energies indicates that eosin $\mathrm{Y}$ is located inside the NTs, and not on the external surfaces of IMO- $\mathrm{CH}_{3}$. The encapsulation of eosin $\mathrm{Y}$ was also evidenced by SAXS experiments (see Figure 2). For incident photons of $150 \mathrm{eV}$ (resp. $400 \mathrm{eV}$ ), the kinetic energy of $\mathrm{Al} 2 \mathrm{p}$ photoelectrons was roughly equal to $70 \mathrm{eV}$ (resp. $320 \mathrm{eV}$ ). The difference in the intensity of the $\mathrm{Al} 2 \mathrm{p}$ signal after normalization by the photon flux and by the photoionization cross section of aluminum for the incident photon energies of both 150 and $400 \mathrm{eV}$ suggests the presence of a $10 \mathrm{~nm}$ water layer on the external surface of $\mathrm{IMO}-\mathrm{CH}_{3}$ containing eosin $\mathrm{Y}$ (see the Supporting Information for details on the calculation). For the purpose of comparison, the size of the agglomerates made of NTs is around $200 \mathrm{~nm}$.

Notably, for these synchrotron-radiation based XPS measurements, the photon flux is the highest when the energy is set at $150 \mathrm{eV}$. Thus, the ratio between the flux obtained for $150 \mathrm{eV}$ photons and $400 \mathrm{eV}$ photons is equal to 3.4. Moreover, as stated in Figure caption 5, the resolution is equal to $320 \mathrm{meV}$ ( $870 \mathrm{meV}$, respectively) when 150 (400, respectively) photons are used. As the flux evolves linearly with the resolution, the flux of $400 \mathrm{eV}$ photons should have been decreased by a factor of 2.7 if the same resolution would have been targeted in both experiments. If we now consider the atomic cross-section of $\mathrm{Si} 2 \mathrm{p}$ (as obtained from PENELOPE simulations), ${ }^{36}$ it is 8.3 higher for $150 \mathrm{eV}$ photons than for $400 \mathrm{eV}$ photons. Therefore, the flux and cross-sections data are clearly in favor of experiments performed with $150 \mathrm{eV}$ photons. This is even more acute if the same resolution is used for both photon energies. In the case of $\mathrm{Br} 3 \mathrm{~d}$ for which the cross-section at $150 \mathrm{eV}$ is 3.6 higher than at 400 $\mathrm{eV}$, the absence of the $\mathrm{Br} 3 \mathrm{~d}$ signal on the spectrum recorded with $150 \mathrm{eV}$ photons (Figure 5) 
clearly shows that bromide atoms are located deep inside, i.e. inside the imogolite nanotubes. Under these conditions, the photon energy had to be increased in order to allow the detection of this element.

These measurements demonstrate the ability of synchrotron XPS experiments performed on isolated objects to probe all the various elements of imogolite and even the ones encapsulated inside (see also Si $2 p$ core level spectra on Figure 7a). Aluminum and silicon spectra can be obtained regardless of the presence of water on the external surfaces. However, the O1s core level spectra are not informative on oxygen atoms present in imogolites, as the signal is dominated by $\mathrm{O} 1 \mathrm{~s}$ photoelectrons arising from water located on the external surface of the nanoparticles (see Figure SI-5 in Supporting Information).

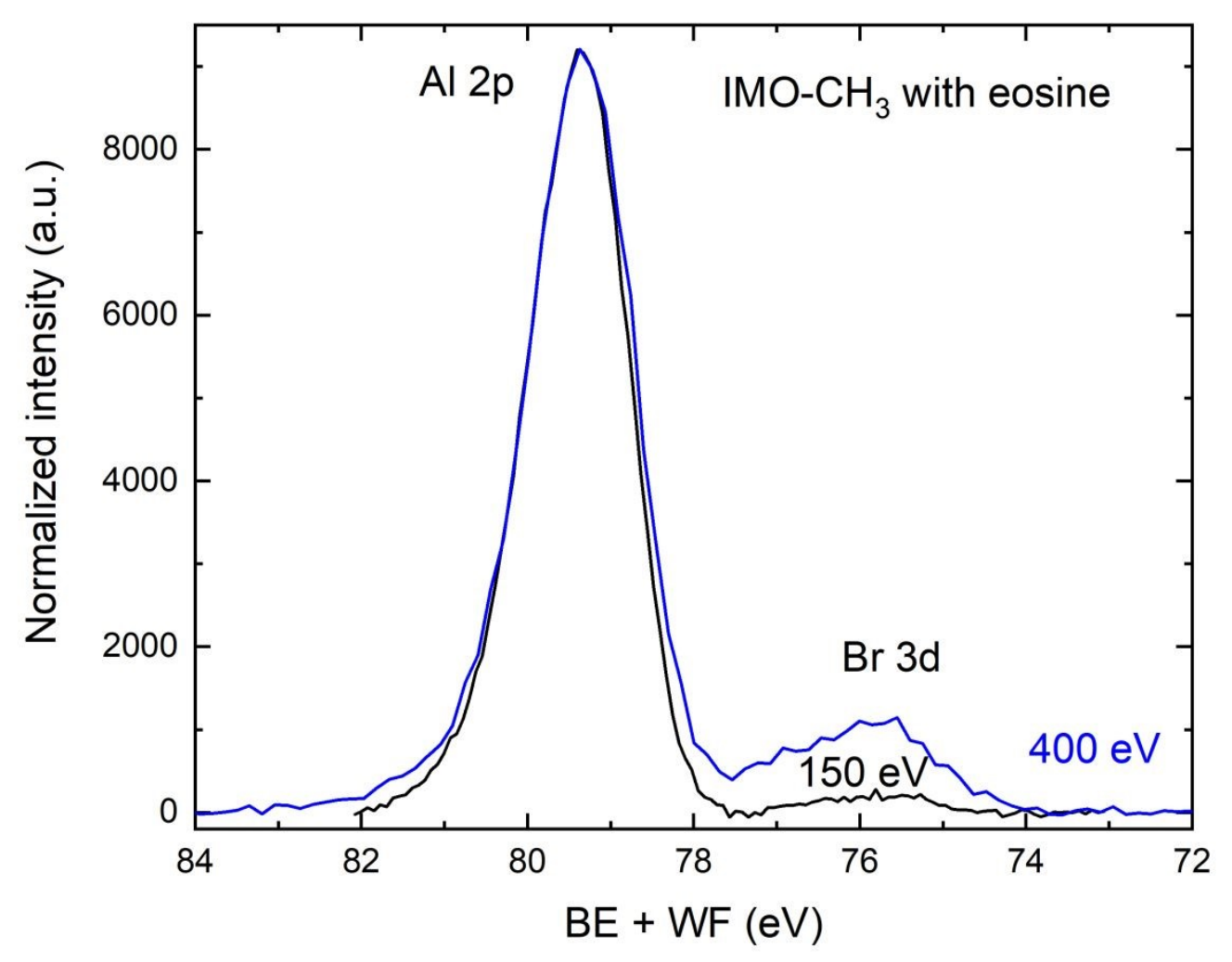

Figure 5. Normalized core-level spectra for isolated $\mathrm{IMO}-\mathrm{CH}_{3}$ containing eosin $\mathrm{Y}$. The incident energy of the photons is $150 \mathrm{eV}$ for the black curve and $400 \mathrm{eV}$ for the blue curve. The total resolution is $320 \mathrm{meV}$ and $870 \mathrm{meV}$ for experiments performed with photons having an energy of 150 and $400 \mathrm{eV}$, respectively. 


\subsection{Detailed discussion of the Si $2 p$ and Al $2 p$ core level spectra of surface- deposited nanotubes obtained from laboratory XPS measurements}

XPS laboratory experiments were performed on surface deposited films for both imogolite types (see Figure $4 \mathrm{a}$ and $4 \mathrm{~b}$ for the survey spectra). The Si $2 \mathrm{p}$ core level spectra have a maximum at a binding energy equal to $102.4 \mathrm{eV}$ and $102.3 \mathrm{eV}$ for IMO-OH and IMO- $\mathrm{CH}_{3}$, respectively (Figures 6 and 7). The binding energies measured in both imogolites are thus very similar. Notably, a value of $101.8 \mathrm{eV}$ was previously reported in grafted $\mathrm{IMO}-\mathrm{CH}_{3} \cdot{ }^{37}$ The $\mathrm{Al} 2 \mathrm{p}$ core level spectra have a maximum at a binding energy equal to $74.7 \mathrm{eV}$ and 74.8 $\mathrm{eV}$ for IMO-OH and IMO- $\mathrm{CH}_{3}$, respectively (Figure 6).

$\mathrm{Si}$ and $\mathrm{Al}$ atoms in imogolite are respectively in tetrahedral and octahedral coordination with oxygen. In IMO-OH, the tube wall consists of a gibbsite-like $\left(\mathrm{Al}(\mathrm{OH})_{3}\right)$ sheet, which is linked through three $\mathrm{Si}-\mathrm{O}-\mathrm{Al}$ bonds to isolated four-coordinated silicon atoms on the internal surface. No substitution in the tetrahedral sites or in the dioctahedral layer exists. The XPS spectra of various flat $2 \mathrm{D}$ clay minerals, all measured under the same conditions, were previously reported by Kloprogge and Wood. ${ }^{38}$ For the sake of comparison, we have selected here the binding energies relative to the $\mathrm{Si} 2 \mathrm{p}$ and $\mathrm{Al} 2 \mathrm{p}$ core level spectra in clay minerals having similar coordinations for Si and Al (Figure 6).

The clay minerals with the most similar local structure are kaolinite (Kao), pyrophillite $(\mathrm{Pyr})^{39}$ and halloysite (Hal), ${ }^{40}$ which are alumuninosilicates with $\mathrm{Si}$ tetrahedral sites and $\mathrm{Al}$ in the dioctahedral layer without any chemical substitutions (Figure 6, green squares). The Si/Al ratio is however different from that of imogolite (which is equal to 0.5). While kaolinite and pyrophillite are flat clay minerals, halloysite is a nanotube like imogolite. However, in halloysite, the Si layer exposes siloxane ( $\mathrm{Si}-\mathrm{O}-\mathrm{Si}$ ) groups toward the external surface and the internal surface is covered by aluminol groups (Al-OH). Thus, the Si $2 \mathrm{p}$ and $\mathrm{Al} 2 \mathrm{p}$ binding energies are very similar for kaolinite and pyrophillite (Figure 6), while the curved clay minerals (halloysite and imogolite) display some differences in binding energies. In particular, in imogolite, the $\mathrm{Al} 2 \mathrm{p}$ binding energy is similar to that reported in kaolinite and pyrophilite, but the Si $2 \mathrm{p}$ binding energy is decreased by about $1 \mathrm{eV}$ as compared to these samples. Interestingly, in halloysite, a tubular structure where $\mathrm{Al}$ and $\mathrm{Si}$ are oppositely distributed as compared to imogolite, with aluminum inside the tubes and silicon outside, the largest shift is instead observed for the $\mathrm{Al} 2 \mathrm{p}$ BE.

We also compared the Al $2 p$ and Si $2 p$ binding energies of flat 2D clay minerals containing substitution in the dioctahedral layer or $\mathrm{Al}$ atoms as substitutions in the $\mathrm{Mg}$ trioctahedral layer 
(blue circles and red triangles in Figure 6, respectively). Substitutions affect both the Al 2p and Si $2 p$ binding energies but with an average amplitude that is never as high as for the Si $2 p$ binding energy in imogolite. Obviously, even if the amount of substitution increases the dispersion of the binding energy values, the binding energies relative to $\mathrm{Al} 2 \mathrm{p}$ spectra of both imogolites are close to those of the other clay minerals, while the binding energies relative to Si $2 p$ are lower in both imogolites than in flat 2D clay minerals. Moreover, while the Si $2 p$ binding energy is equal to $103.6 \mathrm{eV}$ in silica gel, ${ }^{41}$ almost no difference could be evidenced in terms of binding energy between $\mathrm{Si}-\mathrm{O}-\mathrm{Si}$ and $\mathrm{Si}-\mathrm{O}-\mathrm{H}^{41}{ }^{4}$ The oxidation number of the oxygen atom is the main factor influencing the value of the $\mathrm{Si} 2 \mathrm{p}$ binding energy. ${ }^{42}$ Therefore, these results suggest that the discrepancy between the $\mathrm{Si} 2 \mathrm{p}$ binding energy in imogolite and in kaolinite or pyrophillite cannot be explained by the number of $\mathrm{Al}$ atoms linked to -OSi. On the contrary, the intra-wall electric field, predicted by DFT, should have a non-negligible influence on the kinetic energy of photoelectrons. Photoelectrons should then gain kinetic energy between the silicon layer and the external surface, leading to an apparent lowering of the Si $2 p$ binding energy. Detailed calculations and discussion about the impact of an intrawall electric field on the photoelectron kinetic energy are provided in the Supporting Information (section on the electric field in the imogolite wall). For IMO-OH, the gain in kinetic energy is found to be $0.7 \mathrm{eV}$. Imogolite can be modeled as a cylindrical capacitor in which the charge accumulation is not the result of an imposed potential difference through an external circuit, but rather the result of opposed charge accumulation due to curvature (see Supporting Information). In such a model, the $\sigma_{\mathrm{e}} / \varepsilon_{\mathrm{r}}$ ratio $\left(\sigma_{\mathrm{e}}\right.$ being the surface charge density on the external surface) is directly related to the potential difference across the nanotube wall (see Supporting Information). For an experimentally determined difference of $0.7 \mathfrak{b}_{\mathfrak{e}} / \varepsilon_{\mathrm{r}}=$ $9.0 \mathrm{mC} \cdot \mathrm{m}^{-2}$. Assuming $\varepsilon_{\mathrm{r}}=5$ as in mica, ${ }^{43}$ we obtain $\sigma_{\mathrm{e}}=45 \mathrm{mCm}^{-2}$ which is in excellent agreement with the estimation of Gustaffson $\left(42 \mathrm{mC} \cdot \mathrm{m}^{-2}\right) .{ }^{15}$ Thus, IMO-OH would have a capacitance of $48 \mathrm{~F} \cdot \mathrm{g}^{-1}$, corresponding to an accumulated electrostatic energy of roughly $10 \mathrm{~kJ}$ $\cdot \mathrm{kg}^{-1}$. This energy represents, however, less than $1 \%$ of the interfacial energy difference which drives the curvature. ${ }^{6}$

The analysis of chemical shifts provides valuable insights into the first coordination of the probed atoms. For instance, the characteristic binding energy of $\mathrm{Si} 2 \mathrm{p}$ is $103.6 \mathrm{eV}$ for $\mathrm{SiO}_{2}$. This value is decreased to $102.8 \mathrm{eV}$ when one oxygen is replaced by one carbon atom. ${ }^{44}$ Thus, the chemical shift for the substitution of the internal -OH group by a $-\mathrm{CH}_{3}$ group cannot be neglected. Knowing that the characteristic binding energy of $\mathrm{Si} 2 \mathrm{p}$ is equal to $101.3 \mathrm{eV}$ in 
$\mathrm{SiC},{ }^{45}$ the replacement of $4 \mathrm{Si}-\mathrm{O}$ bonds by $4 \mathrm{Si}-\mathrm{C}$ bonds leads to a $2.3 \mathrm{eV}$ decrease of the binding energy. Therefore, we can assume that the replacement of one $\mathrm{Si}-\mathrm{O}$ bond by one $\mathrm{Si}-\mathrm{C}$ bond, as it is the case when changing IMO-OH for $\mathrm{IMO}-\mathrm{CH}_{3}$, leads roughly to a decrease of $0.6 \mathrm{eV}$ of the binding energy. Taking into account the contribution of the chemical shift, the gain in kinetic energy for IMO- $\mathrm{CH}_{3}$ is thus much lower than in IMO-OH with a typical value of $0.2 \mathrm{eV}$. Following the same calculations as described above, then $\sigma_{\mathrm{e}} / \varepsilon_{\mathrm{r}}=2.6 \mathrm{mC} \cdot \mathrm{m}^{-2}$, leading to $\sigma_{\mathrm{e}}=13 \mathrm{mC} \cdot \mathrm{m}^{-2}$, if we assume that $\varepsilon_{\mathrm{r}}=5$ in $\mathrm{IMO}-\mathrm{CH}_{3}$. Notably, the value of the relative permittivity may be different in IMO-OH and IMO- $\mathrm{CH}_{3}$. Therefore, IMO- $\mathrm{CH}_{3}$ has a lower potential difference across its wall than IMO-OH, and a lower external surface charge density.

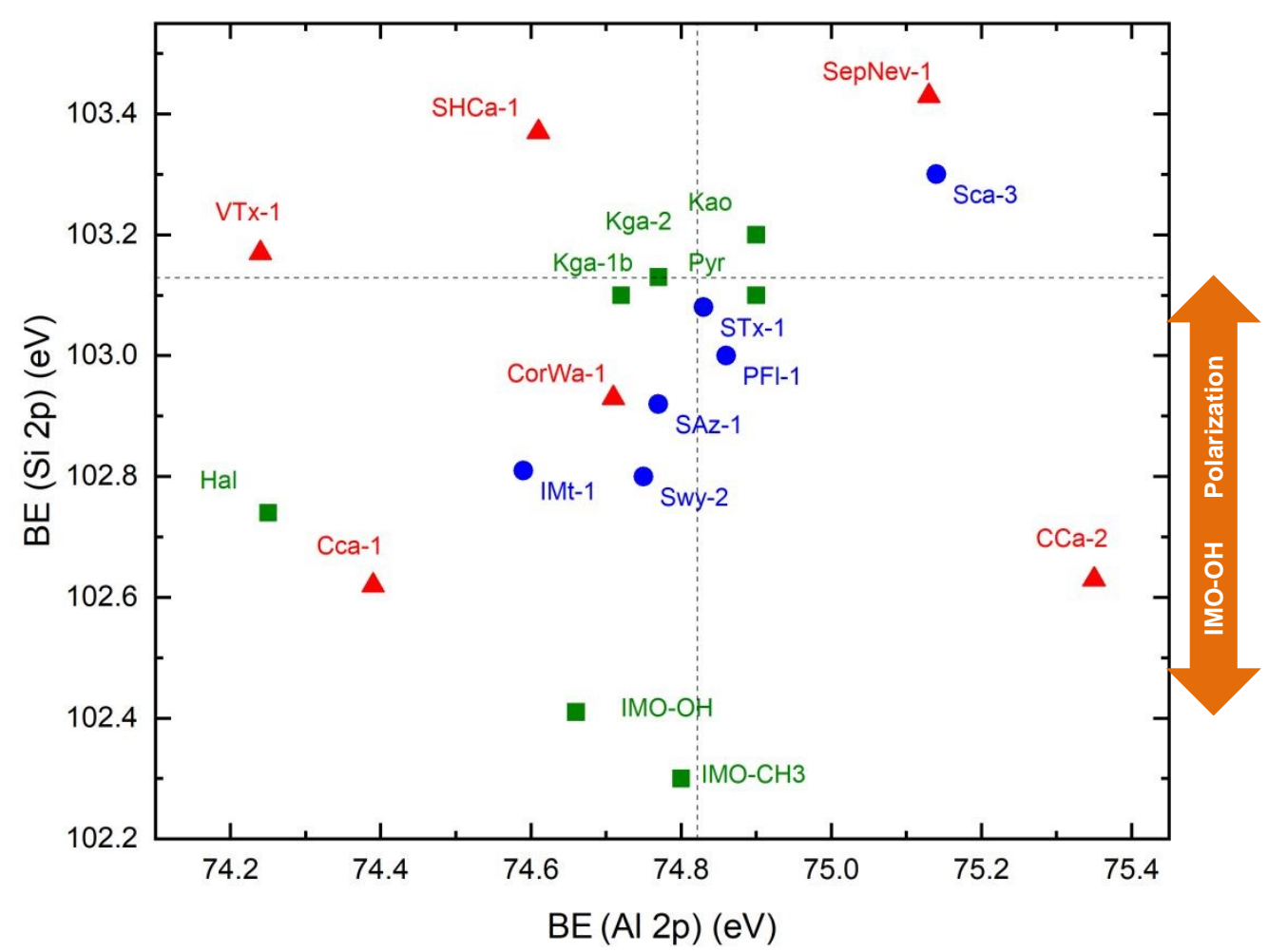

Figure 6. Si $2 p$ and Al $2 p$ binding energies relative to the Fermi level plotted for IMO-OH and IMO-CH $\mathrm{I}_{3}$ (both by green squares). Chemically similar but flat clay minerals (except for halloysite) are also displayed for comparison. The corresponding values can be found in references. ${ }^{38,39-40}$ The binding energies for kaolinite and pyrophillite ${ }^{39}$ are corrected by adding $0.4 \mathrm{eV}$ to calibrate for the adventitious carbon at $285.0 \mathrm{eV}$ as for the other binding energies represented in this graph. The colors and symbols indicate the type of octahedral aluminum, whether in the dioctahedral layer without substitution (green squares), or with substitution (blue circles). Lastly, clay minerals for which octahedral aluminums are found as substitutions in the $\mathrm{Mg}$ trioctahedral layer are represented as red triangles. KGa-1b is 
kaolinite (Washington, Georgia); KGa-2 is kaolinite (Warren, Georgia); SWy-2 is montmorillonite (Wyoming); SAz-1 is montmorillonite (Arizona); STx-1 is montmorillonite (Texas); SCa-3 is montmorillonite (California); SHCa-1 is hectorite (California); IMt-1 is illite (Montana); PFl-1 is palygorskite (Florida); SepNev-1 is sepiolite (Nevada); VTx-1 is vermiculite (Texas);CorWa-1 is corrensite (Washington); $\mathrm{CCa}-1$ and $\mathrm{CCa}-2$ are ripidolite from California, ${ }^{38}$ Kao is kaolinite (location not indicated) ${ }^{39}$; Pyr is pyrophillite (location not indicated $)^{39}$ and Hal is halloysite (Poland) ${ }^{40}$. The dotted lines indicate the average values obtained for the various kaolinites and for pyrophillite. On the right, the orange arrow represents the polarization effect in IMO-OH whereas the purple ones indicate the contributions of chemical shift and polarization in $\mathrm{IMO}_{-} \mathrm{CH}_{3}$.

\subsection{Detailed discussion of the Si $2 p$ and Al $2 p$ core level spectra of isolated nanotubes}

The difference between the XPS measurements on isolated nanotubes and on surface deposited nanotubes for various samples makes it possible to compare the relative values of their WFs (Figure 4c). In the case of IMO-OH, the maximum of the Si 2p core level spectra was located at 102.4 and $107.2 \mathrm{eV}$ for laboratory and synchrotron radiation-based experiments, respectively. In this latter case, the total resolution of the spectra displayed in Figure 7 is, in all cases, equal to $72 \mathrm{meV}$. These values were 74.7 and $79.4 \mathrm{eV}$ in the case of the $\mathrm{Al} 2 \mathrm{p}$ core level spectra. Therefore, the work function (WF) is equal to $4.75 \pm 0.20 \mathrm{eV}$ for IMO-OH (Figure 7), the error bar representing the standard deviation from various measurements $(n=5)$. In the case of $\mathrm{IMO}-\mathrm{CH}_{3}$, the corresponding values were calculated as 102.3 and $106.7 \mathrm{eV}$ for the Si 2p core level spectra and 74.8 and $79.3 \mathrm{eV}$ for the $\mathrm{Al} 2 \mathrm{p}$ core level spectra (Figure 7). The WF is then equal to $4.45 \pm 0.25 \mathrm{eV}$ for $\mathrm{IMO}-\mathrm{CH}_{3}$, the error bar representing the standard deviation from various measurements $(n=5)$. Even if the surface of the nanoparticles was covered with water in the experiments based on isolated samples, which is not the case when deposited samples are studied, the comparison between both experiments gives access to the WF value. Indeed, water is sorbed on the outer surface of the tubes. Even though there are $\mathrm{H}$ bonds between $-\mathrm{OH}$ and the first molecular water layer, there is no covalent bond that could change the electronic structure of the material, and therefore change the WF. This was already pointed out for a study on $\mathrm{TiO}_{2}$ nanoparticles. ${ }^{21}$ The value of the WF was then confidently obtained.

Notably, typical values of WFs usually range between 3 and $5 \mathrm{eV},{ }^{46}$ which is consistent with our measurements. The value measured in hybrid imogolite is a little bit smaller than that of native IMO-OH. This can be related to the change in the surface charge density. Indeed, a change in electrostatic effects at interfaces has an influence on the value of the WF, ${ }^{47-49}$ and 
the value of the WF was shown to increase with that of the dipole moment on the surface. ${ }^{48}$ This also suggests that IMO- $\mathrm{CH}_{3}$ has a smaller surface charge density than IMO-OH, which is in agreement with our findings in the previous section.

In surface-deposited samples, the $\mathrm{Br} 3 \mathrm{~d}_{3 / 2}$ and $\mathrm{Br} 3 \mathrm{~d}_{5 / 2}$ doublet of bromine in eosin were reported to be detected at 69.6 and $68.5 \mathrm{eV}$ in reference ${ }^{50}$ and at 70.3 and $69.5 \mathrm{eV}$, respectively, in reference. ${ }^{51}$ They were located at 77.2 and $76.0 \mathrm{eV}$, respectively, for eosin $\mathrm{Y}$ encapsulated in IMO- $\mathrm{CH}_{3}$, when experiments were performed on isolated samples (Figure 5). This $7 \mathrm{eV}$ difference suggests that molecules encapsulated in the imogolite nanotube undergo polarization effects.
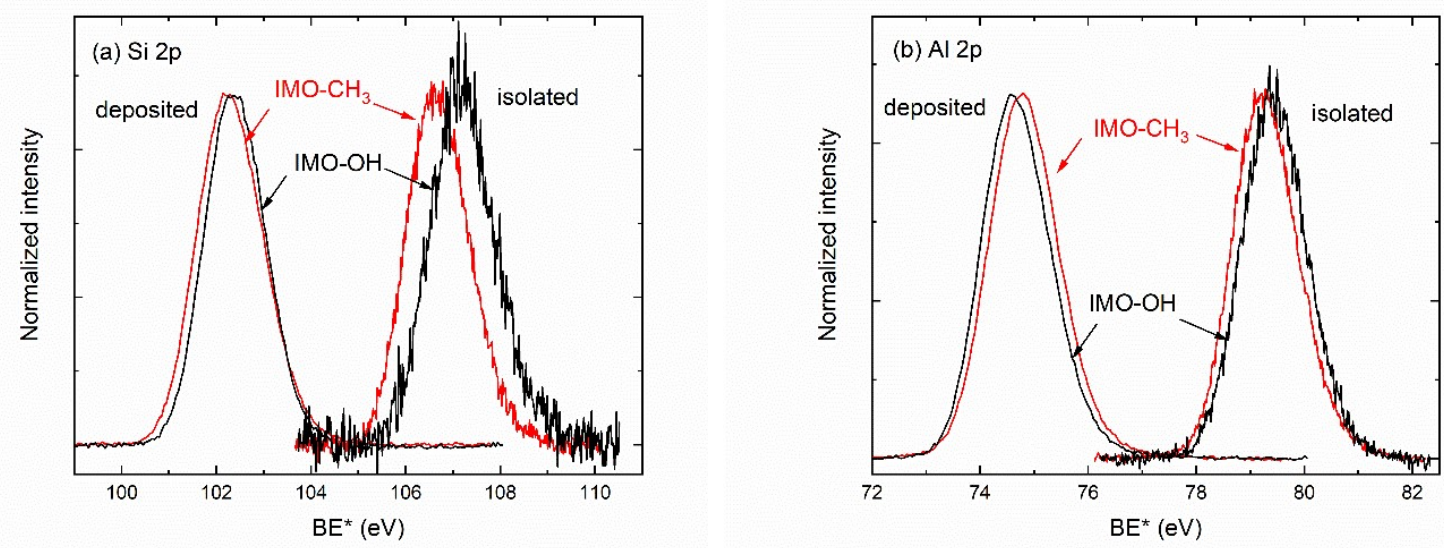

Figure 7. Normalized (a) Si $2 p$ and (b) Al $2 p$ core level spectra for IMO-OH (in black) and $\mathrm{IMO}_{-} \mathrm{CH}_{3}$ (in red). The spectra of deposited (left) and isolated (right) samples are shown on both figures. For the experiments on deposited samples, the atomic core level binding energy $(B E)$ is directly obtained from the measurement of $\Phi^{s p}$. In this case, $B E^{*}$ is then equal to $B E$. For measurements on isolated samples performed with a photon energy of $150 \mathrm{eV}$, the kinetic energy is calibrated with respect to the vacuum level and $B E+W F$ is measured. In this case, $B E^{*}$ is then equal to $B E+W F$. The difference between the values obtained by both techniques gives the work function (WF) of each sample.

\subsection{Band diagrams of IMO-OH and $\mathrm{IMO}-\mathrm{CH}_{3}$}

The band gap energy values of IMO-OH and $\mathrm{IMO}-\mathrm{CH}_{3}$ were experimentally determined to be equal to $5.85 \pm 0.30 \mathrm{eV}$ and $5.4 \pm 0.2 \mathrm{eV}$, respectively (see Figure 3). Moreover, our measurements indicate a direct transition band gap in both cases (see section 2.1.2 with Figure 3). The value measured in IMO-OH is higher than that predicted in IMO-OH using first- 
principles calculations $(5.2-5.3 \mathrm{eV}) \cdot{ }^{17}$ It is also higher than the values simulated in reference ${ }^{18}$ (around $4.7 \mathrm{eV}$ for IMO- $\mathrm{CH}_{3}$ ). However, the authors stress that the thus-calculated value of the band gap is underestimated. ${ }^{18}$ Furthermore, compared to model imogolites used for the calculations, the measured samples have defects, ${ }^{19}$ which can affect the value of the band gap. ${ }^{52}$

The valence spectra of IMO-OH and IMO- $\mathrm{CH}_{3} \mathrm{NTs}$, measured with respect to the vacuum level on isolated samples, are shown in Figure 8a. The total resolution of the valence band measurements is equal to $65 \mathrm{meV}$. The top level of the valence band can be obtained from the intercept of the linear fit with the $\mathrm{x}$-axis (Figure $8 \mathrm{a}$ ). It is equal to $-8.65 \pm 0.07 \mathrm{eV}$ and $-8.45 \pm$ $0.07 \mathrm{eV}$ for IMO-OH and IMO- $\mathrm{CH}_{3}$, respectively. Interestingly, no band gap states were observed (Figure 8a). We call attention to the fact that these experiments were performed on isolated samples; one major asset is that they do not require any complex preparation. For the purpose of comparison, the valence spectra of bulk water and of both imogolites, measured under the same experimental conditions, were compared (see Figure SI-6 in Supporting Information). Clearly, the signals we observe in both imogolites are markedly different from that of bulk water. Notably, the valence spectrum of water is narrower than the valence spectra of imogolites (Figure SI-6 in Supporting Information), as the full width at half maximum is equal to $2.9 \mathrm{eV}$ for water and to $3.9 \mathrm{eV}$ for IMO-OH and $\mathrm{IMO}-\mathrm{CH}_{3}$, suggesting that the spectra of imogolites contain the contributions of surface water and of the material itself.

We also measured the valence spectra of deposited imogolites (see Figure SI-7 in Supporting Information). The global shape is similar for both inorganic nanotubes, and is different from that measured on isolated samples. This shape is consistent, although less structured, with previous calculations of vacuum aligned density of states (DOS), even though the bands we measured are wider than those calculated. ${ }^{18}$ From the intercept of the linear fit to the data with the X-axis (Figure SI-7 in Supporting Information) and from the values of the work function for IMO-OH and $\mathrm{IMO}-\mathrm{CH}_{3}$, we can estimate, from these laboratory experiments, that the top level of the valence band is equal to -8.35 and $-8.45 \mathrm{eV}$ for IMO-OH and IMO- $\mathrm{CH}_{3}$, respectively. This is consistent with the values measured on isolated samples (-8.65 and -8.45 $\mathrm{eV}$, respectively), even if the samples are different in both cases. Indeed, the deposited samples are dried under vacuum while the isolated ones contain water. All these results suggest that the valence spectra measured on isolated samples contain contributions from 
surface water and from imogolite, and that this latter component prevails at the lowest energy values, when the position of the top level of the valence band is measured.

From the valence band edge and band gap energy values, the band diagrams of both imogolites could be obtained (Figure $8 \mathrm{~b}$ ). The measured energies of the band edges of imogolites are lower in energy than values calculated previously. ${ }^{18}$ Nevertheless, DFT simulations are known to overestimate and underestimate the valence band edge and the conduction band edge, respectively. ${ }^{18}$ Importantly, calculations have predicted a real-space separation of the valence and conduction band edges, with states arising from the oxygen atoms of the silica tetrahedra on the inner wall of the tubes in the first case, and states due the hydroxyl groups located on the external surface of the tubes in the latter one. ${ }^{17-18}$

Obviously, in both cases, the Fermi level is closer to the bottom of the conduction band than to the top of the valence band. In the case of an oxide, Matsumoto ${ }^{53}$ stressed that the energy band edges positions are determined by the Madelung energy, the electron affinity of oxygen. This implies that the energy band edges positions $\left(E_{c}\right.$ and $E_{v}$ for the positions of the conduction and valence band edges, respectively, expressed in $\mathrm{V}$ with respect to the Normal Hydrogen Electrode, NHE) mainly depend on the band gap values: ${ }^{53}$

$$
E_{c}=1.23-\frac{E_{g}}{2} ; E_{v}=1.23+\frac{E_{g}}{2}(\text { in V) (Eq. } 4)
$$

These expressions hold for both imogolites as the calculated values $(-1.70 \mathrm{~V}$ and $-1.47 \mathrm{~V}$ for $E_{c} ; 4.16 \mathrm{~V}$ and $3.93 \mathrm{~V}$ for $E_{v}$, for IMO-OH and $\mathrm{IMO}^{-\mathrm{CH}_{3}}$, respectively) are very similar to those measured (Figure $8 \mathrm{~b}$, i.e. $-1.70 \mathrm{~V}$ and $-1.45 \mathrm{~V}$ for $E_{c} ; 4.15 \mathrm{~V}$ and $3.95 \mathrm{~V}$ for $E_{v}$, for IMO-OH and IMO- $\mathrm{CH}_{3}$, respectively). This is also represented in Figure SI-8 in the Supporting Information.

This comparison shows that although imogolite is a nanotube possessing wall polarization, it behaves, from an electrochemical point of view, as the other oxides previously studied by Matsumoto $^{53}$. The band diagrams of various oxides are displayed in Figure $8 \mathrm{c}$ for the sake of comparison. Even if the value of the band gap of imogolites is high, the position of their band edges makes them potential candidates for water splitting (Figures $8 \mathrm{~b}$ and 8c). Indeed, the conduction band edges of both imogolites have a more negative redox potential than $\mathrm{H}^{+} / \mathrm{H}_{2}(0$ $\mathrm{V}$ vs. NHE at $\mathrm{pH}=0$ ), while their valence band edges have a more positive redox potential than $\mathrm{O}_{2} / \mathrm{H}_{2} \mathrm{O}(+1.23 \mathrm{~V}$ vs. NHE at $\mathrm{pH}=0)$ (Figures $8 \mathrm{~b}$ and $\left.8 \mathrm{c}\right) .{ }^{54}$ The band diagram of both imogolites is very similar to that of $\mathrm{ZrO}_{2}$, which has a similar band gap value (Figure 8c). In fact, the photocatalytic properties of $\mathrm{ZrO}_{2}$ have been investigated. ${ }^{55-56}$ However, compared to 
this oxide, imogolite offers many advantages: i) it is made of low cost, abundant and benign elements; ii) its high curvature induces an intra-wall electric field favorable for charge separation; iii) the chemical functional groups inside its cavity can be changed in order to allow the encapsulation of organic molecules in aqueous media.
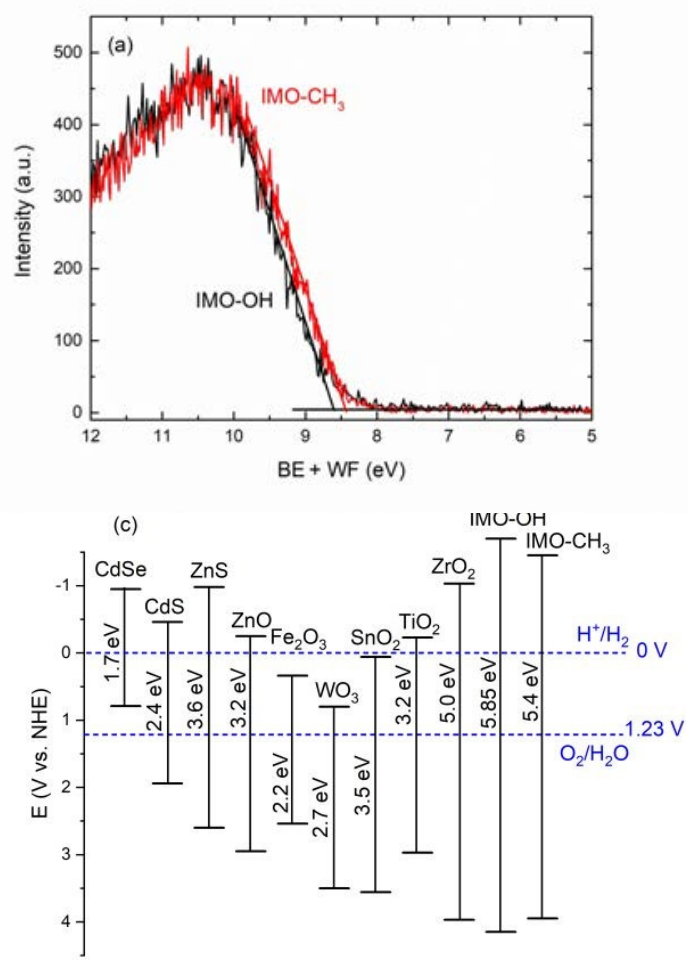

(b)

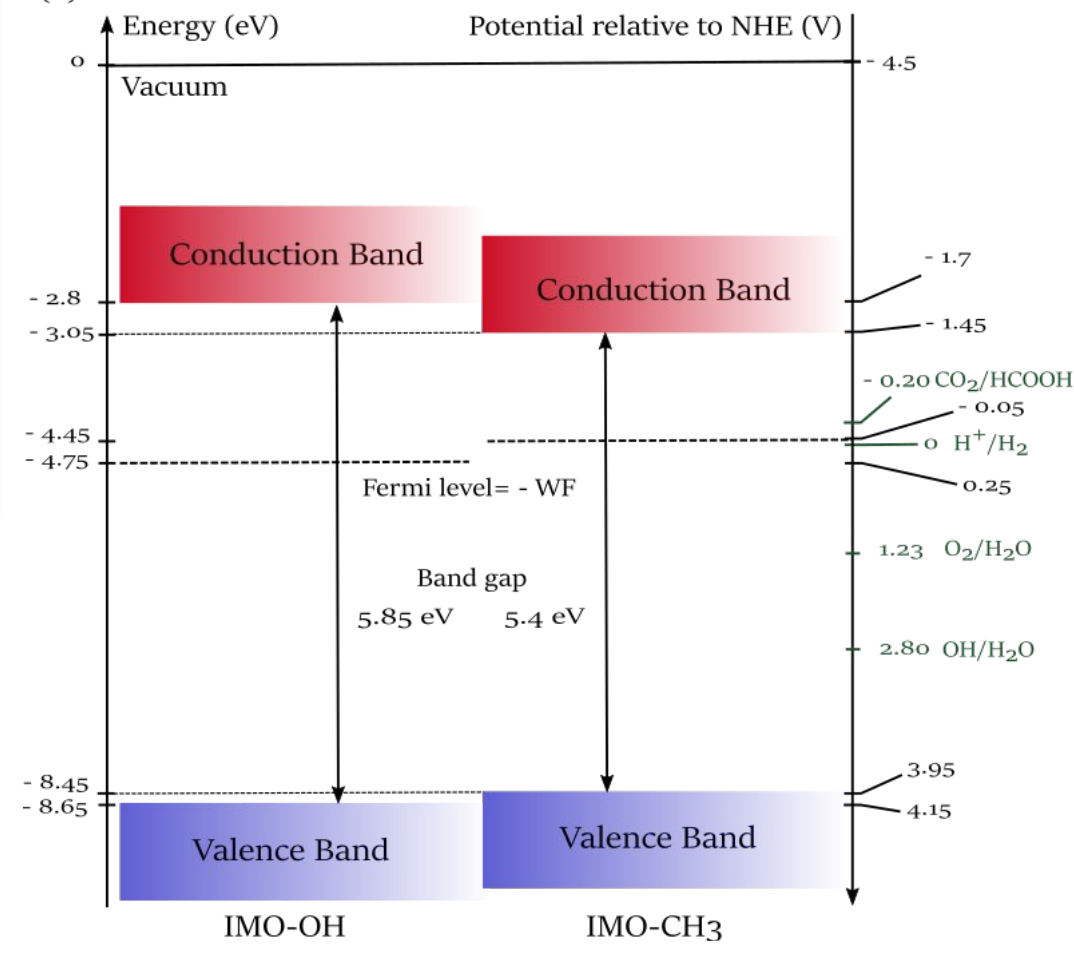

Figure 8. (a) Valence spectra of hydrated IMO-OH (in black) and $\mathrm{IMO}^{-\mathrm{CH}_{3}}$ (in red) measured using synchrotron radiation-based XPS of isolated nanotubes at $100 \mathrm{eV}$ photon energy. The spectra are normalized with respect to the top of the valence band. The zero energy corresponds to the vacuum level. The linear fits enable measuring the energy of the top of the valence bands. (b) Schematics of the band diagrams of IMO-OH and IMO-CH . The various energies are given in absolute ( $\mathrm{eV}$ ) and also in relative (in $\mathrm{Vvs}$. NHE) potential scale. The band edges of imogolites are also represented relative to the reversible oxidation and reduction potential of water (at $\mathrm{pH}=0$ ). (c) Band edges of selected compounds. The values of the band edges are taken from reference ${ }^{57}$.

\section{Conclusions}

In this work, we have demonstrated the presence of a significant intra-wall polarization in imogolite, and we have provided its experimental quantification $(0.7 \mathrm{~V}$ in IMO-OH and 
around $0.2 \mathrm{~V}$ in $\mathrm{IMO}-\mathrm{CH}_{3}$ ). Moreover, we have used diffuse reflectance spectroscopy and a unique combination of various XPS techniques (on deposited or isolated samples) to obtain the experimental band diagrams of both imogolites. These diagrams evidence that imogolites are potentially interesting candidates for water splitting reactions, among others. We have also shown that imogolites store part of their curvature driving energy into electrostatic energy. It could be interesting to explore this feature in other oxide nanotubes. Indeed, XPS data of halloysite suggest that a similar intra-wall electric field may exist. However, imogolite processes a huge curvature and a very thin wall and may well be difficult to surpass in this particular feature.

Our results reinforce the strategic interest in imogolite as an anti-electron/hole pair recombination material. Even if the large band gap of IMO-OH and $\mathrm{IMO}-\mathrm{CH}_{3}$ is not favorable because of the low amount of high energy photons present in the solar spectrum, two strategies are possible to overcome this issue and to take advantage of both the hollowness and polarization of imogolites. Firstly, these materials can act as co-catalysts. Thus, coupling IMO- $\mathrm{CH}_{3}$ with an internal antenna able to transfer electrons to the conduction band could trigger external reduction reactions under visible light. Indeed, $\mathrm{IMO}-\mathrm{CH}_{3}$ is very appealing as it can encapsulate organic molecules. Other possible couplings can be envisioned in order to take advantage of the charge separation properties of the $\mathrm{IMO}-\mathrm{CH}_{3}$ polarized wall to drive different redox reactions, both in the cavity of the nanotubes (oxidation) and on the external surfaces (reduction). The second strategy consists in doping the imogolite wall to reduce the band gap, for instance with iron. This has already been performed by several researchers for

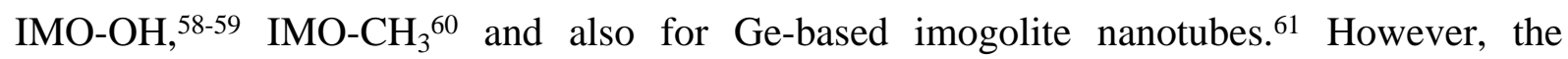
photocatalytic properties of such iron-doped imogolite have not yet been fully explored. ${ }^{60,62}$ These strategies open the way to the practical use of imogolite, where its unique electrochemical properties and sustainability highlight its appeal as photochemical nanoreactor.

\section{Experimental details}

\subsection{Sample preparation}

Native imogolite (IMO-OH) was synthesized following methods inspired by Farmer et al. ${ }^{9-10}$ All chemicals were used as received. $\mathrm{AlCl}_{3}$ (Alfa Aesar, 99\%) was dissolved in MilliQ water at a concentration of $2 \mathrm{mM}$ together with tetraethoxysilane (TEOS, Aldrich, 98\%) at a Si/Al 
molar ratio of 0.55 . A slightly higher ratio than the stoichiometric $\mathrm{Si} / \mathrm{Al}$ ratio (0.5) was used to prevent the formation of undesired aluminum hydroxides (gibbsite). Under continuous stirring, $\mathrm{NaOH}$ (Sigma-Aldrich, $\geq 97 \%$ ) was slowly introduced in the solution at a rate of 0.5 $\mathrm{mM} \cdot \mathrm{min}^{-1}$ until an $\mathrm{OH} / \mathrm{Al}$ molar ratio of 2.0 was reached. The suspension was stirred for $1 \mathrm{~h}$ after $\mathrm{NaOH}$ addition until the solution was completely clear. The suspension was then placed in an oven for 5 days at a temperature of $90^{\circ} \mathrm{C}$. After heating, the suspension was concentrated by tangential ultrafiltration using $8 \mathrm{kDa}$ membranes. The concentrated suspension was then dialyzed using the same cutoff against MilliQ water.

Hybrid imogolite (IMO- $\mathrm{CH}_{3}$ ) was prepared using a protocol inspired by Bottero et al. ${ }^{12}$ Aluminum-tri-sec-butoxide (ASB, Aldrich, 97\%) was added to $800 \mathrm{~mL}$ of a $40 \mathrm{mM}$ $\mathrm{HCl}_{\mathrm{aq}}$ solution prepared from Sigma-Aldrich (ACS reagent, 37\%) with an $\mathrm{HCl} / \mathrm{Al}$ molar ratio of 0.5 and stirred for $1 \mathrm{~h}$. Trimethoxymethylsilane (Aldrich, 99\%) was slowly added to obtain a Si/Al molar ratio of 0.6. As for $\mathrm{IMO}-\mathrm{OH}$, this molar ratio is higher than the stoichiometric ratio of 0.5 to avoid the production of aluminum hydroxides by-products. ${ }^{63}$ The dispersion was then heated in an oven for 5 days at $90^{\circ} \mathrm{C}$. Lastly, the dispersion was dialyzed against Milli-Q water using an $8 \mathrm{kDa}$ membrane. The imogolite concentration in the various dispersions under study was $8.2 \mathrm{~g} \cdot \mathrm{L}^{-1}$ for $\mathrm{IMO}-\mathrm{CH}_{3}$ and $6 \mathrm{~g} \cdot \mathrm{L}^{-1}$ for IMO-OH.

To obtain powder for the UV-visible diffuse reflectance measurements, both types of imogolite dispersions were freeze-dried at $-57{ }^{\circ} \mathrm{C}$ under vacuum $(0.035 \mathrm{mbar})$ using a Christ BETA 1-8 LDplus freeze-dryer.

Eosin Y $\left(2^{\prime}, 4^{\prime}, 5^{\prime}, 7^{\prime}\right.$-Tetrabromofluorescein) encapsulated in $\mathrm{IMO}-\mathrm{CH}_{3}$ was prepared by stirring eosin Y powder (Sigma-Aldrich, 99\%) in large excess (>> $200 \mathrm{mg}^{-\mathrm{g}^{-1}}$ of imogolite) in an aqueous suspension of $\mathrm{IMO}-\mathrm{CH}_{3}$ for 12 hours. Excess eosin $\mathrm{Y}$ powder was removed by centrifugation.

\subsection{Characterization of the synthesized imogolites}

\subsubsection{Small-angle X-ray scattering}

Small-angle X-ray scattering (SAXS) measurements of imogolite (both IMO-OH and IMO$\mathrm{CH}_{3}$ ) suspensions in water were performed using a Xeuss 2.0 laboratory X-ray beamline (Xenocs) at a wavelength of $1.542 \AA(\mathrm{Cu} \mathrm{K \alpha})$ under vacuum. The scattering vector is $q=$ 
$4 \pi \cdot \sin (\theta) \cdot \lambda^{-1}$, where $\lambda$ is the wavelength and $2 \theta$ is the scattering angle. The displayed $q$ range from 0.0037 to $1.10 \AA^{-1}$ was attained with two sample-to-detector distances. The sample-todetector distance was calibrated with tetradecanol as a standard and the detector count was normalized by direct beam measurements. The imogolite suspensions were analyzed in sealed glass capillaries with a diameter of $1.5 \mathrm{~mm}$. Standard procedures were applied to subtract the background scattering and to correct the raw scattering profiles by using a measurement of an empty capillary to normalize the intensities. ${ }^{64}$

\subsubsection{X-ray photoelectron spectroscopy (XPS)}

\section{Laboratory measurements on deposited imogolite samples}

X-ray photoelectron spectroscopy (XPS) was performed with a hemispheric analyzer Kratos Analytical Axis Ultra DLD spectrometer, using an Al Ka source monochromatized at 1486.6 $\mathrm{eV}$ and a charge compensation system. A pass energy of $160 \mathrm{eV}$ was used for the survey spectra and of $20 \mathrm{eV}$ for core levels measurements. The energy resolution of the source and of the analyzer was found to be $0.35 \mathrm{eV}$. The imogolite suspensions were deposited on a glass substrate coated with a $200 \mathrm{~nm}$ layer of gold, enabling simultaneous energy calibration from $\mathrm{Au} 4 \mathrm{f}$. For the valence spectra measurement, powder of imogolite was deposited on a carbon tape. The transfer of the sample to the analysis chamber of the XPS set-up was performed when the pressure of the introduction chamber was low enough to allow this transfer. Typical pressure in the analysis chamber is $1.3 \times 10^{-9}$ mbar. In order to facilitate comparison to the results of Kloprogge et al., ${ }^{38}$ calibration was performed by using adventitious carbon (reference set at $285.0 \mathrm{eV}$ ). Nevertheless, we also verified using the calibration with $\mathrm{Au} 4 \mathrm{f}_{7 / 2}$ (line at $83.96 \mathrm{eV}$ ) that the binding energies obtained by both methods were the same. ${ }^{32,65}$ As $\mathrm{C} 1 \mathrm{~s}$ core level spectra are used only for calibration purposes, they are not given in the text.

Data acquisition and processing were carried out using Casa XPS processing software. After calibration, the background of each spectrum was subtracted using a Shirley-type background. The experimental spectra were fitted using mixed Lorentzian (70\%)-Gaussian (30\%) contributions.

Synchrotron-based XPS on an in-vacuum jet of isolated nanoparticles 
Synchrotron-based soft X-ray photoelectron spectroscopy measurements were also performed in order to evaluate the work function of the samples and to determine the position of their valence band. The experiments were carried out at the SOLEIL synchrotron facility using the soft X-ray PLEIADES beamline (9-1000 eV). The photoelectron spectra were recorded with a commercial wide-angle lens spectrometer (VG-Scienta R4000) based on a hemispherical electron analyzer whose detection axis is perpendicular to the plane of the electron orbit in the storage ring. The pass energy and the entrance slit were selected according to the experimental resolution targeted for each measurement. The total resolution is given below in each case. The polarization vector of the linearly polarized synchrotron beam was chosen to be parallel to the electron detection axis. Samples were introduced to the beam as a flow of nanoparticles sprayed out in the aerosol phase using a carrier gas (Ar). The resulting solid aerosol was focused using an aerodynamic lens system (ADLS) and injected through a $2 \mathrm{~mm}$ skimmer into the high vacuum chamber of the photoelectron spectrometer set-up, where the pressure is kept around $2 \times 10^{-6}$ mbar during experiments. More details on the experiments can be found in references ${ }^{20-21,66-67}$. The kinetic energy of the photoelectrons were calibrated using the $3 \mathrm{~s}$ and $2 \mathrm{p}$ lines of $\mathrm{Ar} .^{29}$ The overall uncertainty of the kinetic energy is estimated to be $0.2 \mathrm{eV}$.

The size of the suspended particles in the aerosol in the gas phase was measured by a scanning mobility particle sizer (TSI Inc., SMPS 3936L86), where mean electrical mobility sizes of about $200 \mathrm{~nm}\left(170 \mathrm{~nm}\right.$ for $\mathrm{IMO}-\mathrm{CH}_{3}$ and $250 \mathrm{~nm}$ for IMO-OH) were recorded. The size distribution of these agglomerates is given in Figure SI-3 in the Supporting Information for both imogolites.

\subsubsection{Determination of the band gap energy values by $U V$-Vis diffuse reflectance} spectroscopy

UV-Vis DRS spectra were measured at room temperature with a Shimadzu UV-2600 spectrometer equipped with an integrating sphere (Shimadzu ISR-2600PLUS). In the present experiment, imogolite films were deposited on a thin quartz surface by the drying of aqueous solutions of imogolite. These films $\left(6.4 \mathrm{mg} \mathrm{cm}^{-2}\right)$ were deposited on a quartz plate (thickness $1 \mathrm{~mm}$ ) mounted on a reflective backing (dense $5 \mathrm{~mm}$ thick $\mathrm{BaSO}_{4}$ layer). An empty quartz plate mounted on a dense $\mathrm{BaSO}_{4}$ backing of same thickness was used as reference. These 
samples were thick enough to satisfy the Kubelka-Munk condition of infinite sample thickness. ${ }^{23}$

\section{Author contributions}

M.-C. P. synthesized the samples. S. P. measured the band gap energy values. All authors performed XPS measurements. M.-C. P., O. S., S. L. C. and A. T. discussed and analyzed the data with the input from all authors. S. L. C. and A. T. wrote the manuscript with the input from all authors.

\section{Conflicts of interest}

There are no conflicts to declare.

\section{Acknowledgments}

Ile de France DIM RESPORE 2019-20 and CEA Bottom Up 2020-21 grants funded this study by the project GRANITE and PHOTOTUBE, respectively. The project has received financial support from Agence Nationale de la Recherche (Project BENALOR, Grant Number ANR20-CE09-0029-02). Synchrotron SOLEIL is acknowledged for providing beam time and technological support. Dr. Frederic Gobeaux is sincerely acknowledged for the transmission electron microscopy images. The authors gratefully thank Dr. Mark Levenstein for reading the manuscript and making insightful comments as well as Dr Luc Belloni for fruitful discussions.

\section{References}

1 M. R. Hoffmann, S. T. Martin, W. Choi and D. W. Bahnemann, Chem. Rev., 1995, 95, 69-96.

2 J. Schneider, M. Matsuoka, M. Takeuchi, J. Zhang, Y. Horiuchi, M. Anpo and D. W. Bahnemann, Chem. Rev., 2014, 114, 9919-9986.

3 F. Chen, H. Huang, L. Guo, Y. Zhang and T. Ma, Angew. Chem. Int. Ed., 2019, 58, 10061-10073. 
4 M. Xiao, Z. Wang, M. Lyu, B. Luo, S. Wang, G. Liu, H.-M. Cheng and L. Wang, Adv. Mater., 2019, 31, 1801369.

$5 \quad$ X. Liu, M. Wang, S. Zhang and B. Pan, J. Environ. Sci., 2013, 25, 1263-1280.

$6 \quad$ A. Thill, P. Picot and L. Belloni, Appl. Clay Sci., 2017, 141, 308-315.

7 L. Guimaraes, A. N. Enyashin, J. Frenzel, T. Heine, H. A. Duarte and G. Seifert, ACS Nano, 2007, 1, 362-368.

8 L. Belloni and A. Thill, Why a 1:1 2d Structure Tends to Roll? A Thermodynamic Perspective. In Nanosized Tubular Clay Minerals. Halloysite and Imogolite, P. Yuan,A. Thilland F. Bergaya, Eds. Elsevier: Amsterdam, 2016; pp 361-386.

9 V. C. Farmer, A. R. Fraser and J. M. Tait, J. Chem. Soc.-Chem. Comm., 1977, 13, 462463.

10 V. C. Farmer, M. J. Adams, A. R. Fraser and F. Palmieri, Clay Miner., 1983, 18, 459472.

11 B. Bonelli, Surface Chemical Modifications of Imogolite. In Nanosized Tubular Clay Minerals. Halloysite and Imogolite, P. Yuanand A. B. Thill, F., Eds. Elsevier: Amsterdam, 2016; pp 279-330.

12 I. Bottero, B. Bonelli, S. E. Ashbrook, P. A. Wright, W. Zhou, M. Tagliabue, M. Armandi and E. Garrone, Phys. Chem. Chem. Phys., 2011, 13, 744-750.

13 P. Picot, F. Gobeaux, T. Coradin and A. Thill, Applied Clay Science, 2019, 178, 4.

14 M.-S. Amara, E. Paineau, S. Rouziere, B. Guiose, M.-E. Krapf , O. Tache, P. Launois and A. Thill, Chem. Mat., 2015, 27, 1488-1494.

15 J. P. Gustafsson, Clays Clay Miner., 2001, 49, 73-80.

16 G. Teobaldi, N. S. Beglitis, A. J. Fisher, F. Zerbetto and W. A. Hofer, J. Phys. Condens. Matter, 2009, 21, 195301.

17 M. Zhao, Y. Xia and L. Mei, J. Phys. Chem. C, 2009, 113, 14834-14837.

18 E. Poli, J. D. Elliott, L. E. Ratcliff, L. Andrinopoulos, J. Dziedzic, N. D. M. Hine, A. A. Mostofi, C.-K. Skylaris, P. D. Haynes and G. Teobaldi, J. Phys.: Condens. Matter, 2016, 28, 074003.

19 M.-C. Pignié, V. Shcherbakov, T. Charpentier, M. Moskura, C. Carteret, S. Denisov, M. Mostafavi, A. Thill and S. Le Caër, Nanoscale 2021, 13, 3092-3105.

20 O. Sublemontier, C. Nicolas, D. Aureau, M. Patanen, H. Kintz, X. Liu, M.-A. Gaveau, J.-L. Le Garrec, E. Robert, F.-A. Barreda, A. Etcheberry, C. Reynaud, J. B. Mitchell and C. Miron, J. Phys. Chem. Lett., 2014, 5, 3399-3403.

21 S. Benkoula, O. Sublemontier, M. Patanen, C. Nicolas, F. Sirotti, A. Naitabdi, F. GaieLevrel, E. Antonsson, D. Aureau, F.-X. Ouf, S.-I. Wada, A. Etcheberry, K. Ueda and C. Miron, Sci. Rep., 2015, 5, 15088.

22 G. Kortüm, W. Braun and G. Herzog, Angew. Chem. Int. Ed., 1963, 2, 333-341.

23 P. Kubelka and F. Munk, Z. Techn. Physik 1931, 12, 593-601.

24 R. Lopez and R. Gomez, J. Sol-Gel Sci. Technol., 2012, 61, 1-7.

25 J. Tauc, R. Grigorovici and A. Vancu, Phys. Status Solidi B, 1966, 15, 627-637.

26 G. Diress Gesesse, A. Gomis-Berenguer, M.-F. Barthe and C. O. Ania, J. Photochem. Photobiol. A: Chem., 2020, 398, 112622.

27 Y. Liao, P. Picot, M. Lainé, J.-B. Brubach, P. Roy, A. Thill and S. Le Caër, Nano Res., 2018, 11, 4759-4773.

28 D. Danilović, D. K. Bozanić, R. Dojcilović, N. Vukmirović, P. Sapkota, I. Vukasinović, V. Djoković, J. Bozek, C. Nicolas, S. Ptasinska and A. R. Milosavljević, J. Phys. Chem. C, 2020, 124, 23930-23937.

29 A. C. Thompson, D. T. Attwood, E. M. Gullikson, M. R. Howells, J. B. Kortright, A. L. Robinson, J. H. Underwood, K.-J. Kim, J. Kirz, I. Lindau, P. Pianetta, H. Winick, G. P. 
Williams and J. H. Scofield, X-Ray Data Booklet; Lawrence Berkeley National Laboratory, University of California: Berkeley, CA, 2009.

30 L. O. Werme, T. Bergmark and K. Siegbahn, Phys. Scr., 1973, 8, 149-158.

31 D. Cahen and A. Kahn, Adv. Mater., 2003, 15, 271-277.

32 G. Greczynski and L. Hultman, Prog. Mat. Sci., 2020, 107, 100591.

33 C. J. Powell, Surf. Interface Anal., 1985, 7, 256-262.

34 S. Tanuma, C. J. Powell and D. R. Penn, Surf. Interface Anal., 2011, 43, 689-713.

35 R. Signorell, Phys. Rev. Lett., 2020, 124, 205501.

36 F. Salvat, J. M. Fernandez-Varea, E. Acosta and J. Sempau PENELOPE- a Code System for Monte Carlo Simulation of Electron and Photon Transport, Nuclear Energy Agency: 2001.

37 C. Zanzottera, A. Vicente, E. Celasco, C. Fernandez, E. Garrone and B. Bonelli, J. Phys. Chem. C, 2012, 116, 7499-7506.

38 J. T. Kloprogge and B. J. Wood, Clay Sci., 2018, 22, 85-94.

39 C. D. Wagner, J. Vacuum Sci. Technol., 1982, 21, 933-944.

40 A. Kubala-Kukus, B. Szczepanik, I. Stabrawa, D. Banas, K. Szary, M. Pajek, P. Rogala, K. Wojtowicz and P. Slomkiewicz, Rad. Phys. Chem., 2020, 175, 108149.

41 T. Gross, M. Ramm, H. Sonntag, W. Unger, H. M. Weijers and E. H. Adem, Surf. Interface Anal., 1992, 18, 59-64.

42 R. Alfonsetti, G. De Simone, L. Lozzi, M. Passacantando, P. Picozzi and S. Santucci, Surf. Interface Anal., 1994, 22, 89-92.

43 Y. L. Ma and J. Karube, Soil Sci. Plant Nutr., 2013, 59, 125-129.

44 S. Roualdes, R. Berjoan and J. Durand, Sep. Purification Technol., 2001, 25, 391-397.

45 I. Kusunoki and Y. Igari, Appl. Surf. Sci., 1992, 59, 95-104.

46 F.-X. Ouf, P. Parent, C. Laffon, I. Marhaba, D. Ferry, B. Marcillaud, E. Antonsson, S. Benkoula, X.-J. Liu, C. Nicolas, E. Robert, M. Patanen, F.-A. Barreda, O. Sublemontier, A. Coppalle, J. Yon, F. Miserque, T. Mostefaoui, T. Z. Regier, J.-B. A. Mitchell and C. Miron, Sci. Rep., 2016, 6, 36495.

47 M. Bruening, E. Moons, D. Cahen and A. Shanzer, J. Phys. Chem., 1995, 99, 83688373.

48 E. L. Bruner, N. Koch, A. R. Span, S. L. Bernasek, A. Kahn and J. Schwartz, J. Am. Chem. Soc., 2002, 124, 3192-3193.

49 M. S. Gärtner, E., G. Nasciembeni, A. Wiesner, M. Kind, P. Werner, C. Schuch, T. Abu-Husein, A. Asyuda, J. W. Bats, M. Bolte, E. Zojer, A. Terfort and M. Zharnikov, J. Phys. Chem. C, 2020, 124, 504-519.

50 H. Lin, H. Ye, X. Li, J. Cao and S. Chen, Ceramics Inter. , 2014, 40, 9743-9750.

51 B. Li, Y. Zhang, F. Duanmu, Y. Shen, Z. Shen and S. Zhong, Photochem. Photobiol. Sci., 2019, 18, 1408-1418.

52 E. Poli, J. D. Elliott, S. K. Chulkov, M. B. Watkins and G. Teobaldi, Front. Chem., 2019, 7, 210.

53 Y. Matsumoto, J. Solid State Chem., 1996, 126, 227-234.

54 A. Kudo and Y. Miseki, Chem. Soc. Rev., 2009, 38, 253-278.

55 S. G. Botta, J. A. Navio, M. C. Hidalgo, G. M. Restrepo and M. Litter, J. Photochem. Photobiol. A: Chem., 1999, 129, 89-99.

56 M. Alvarez, T. Lopez, J. A. Odriozola, M. A. Centeno, M. I. Dominguez, M. Montes, P. Quintana, D. H. Aguilar and R. D. Gonzalez, Appl. Cat. B: Environ., 2007, 73, 34-41.

57 Y. Xu and M. A. A. Schoonen, Am. Mineralogist, 2000, 85, 543-556.

58 M. Ookawa, Y. Inoue, M. Watanabe, M. Suzuki and T. Yamaguchi, Clay Sci., 2006, 12, 280-284. 
59 E. Shafia, S. Esposito, M. Armandi, M. Manzoli, E. Garrone and B. Bonelli, Microporous Mesoporous Mat., 2016, 224, 229-238.

60 E. Bahadori, V. Vaiano, S. Esposito, M. Armandi, D. Sannino and B. Bonelli, Catalysis Today, 2018, 304, 199-207.

61 A. Avellan, C. Levard, N. Kumar, J. Rose, L. Olivi, A. Thill, P. Chaurand, D. Borschneck and A. Masion, RSC Adv., 2014, 4, 49827-49830.

62 E. Shafia, S. Esposito, M. Armandi, E. Bahadori, E. Garrone and B. Bonelli, Catalysis Today, 2016, 277, 89-96.

63 P. Picot, Y. Liao, E. Barruet, F. Gobeaux, T. Coradin and A. Thill, Langmuir, 2018, 34, 13225-13234.

64 P. Lindner, Scattering Experiments: Experimental Aspects, Initial Data Reduction and Absolute Calibration. In Neutrons, X-Rays and Light: Scattering Methods Applied to Soft Condensed Matter, P. Lindnerand T. Zemb, Eds. Elsevier: Amsterdam, 2002; pp 23-48.

65 M. P. Seah, Surf. Interface Anal., 2001, 31, 721-723.

66 A. Lindblad, J. Söderström, C. Nicolas, E. Robert and C. Miron, Rev. Sci. Instrum., 2013, 84, 113105.

67 C. Miron and M. Patanen, Adv. Mater., 2014, 26, 7911-7916. 